ArgOrational laboratory

ANL/ESD/09-6

\title{
Ocean Thermal Plantships for Production of Ammonia as the Hydrogen Carrier
}

Energy Systems Division 


\begin{abstract}
About Argonne National Laboratory
Argonne is a U.S. Department of Energy laboratory managed by UChicago Argonne, LLC under contract DE-AC02-06CH11357. The Laboratory's main facility is outside Chicago, at 9700 South Cass Avenue, Argonne, Illinois 60439. For information about Argonne and its pioneering science and technology programs, see www.anl.gov.
\end{abstract}

\title{
Availability of This Report
}

This report is available, at no cost, at http://www.osti.gov/bridge. It is also available on paper to the U.S. Department of Energy and its contractors, for a processing fee, from:

U.S. Department of Energy

Office of Scientific and Technical Information

P.O. Box 62

Oak Ridge, TN 37831-0062

phone (865) 576-8401

fax (865) 576-5728

reports@adonis.osti.gov

\begin{abstract}
Disclaimer
This report was prepared as an account of work sponsored by an agency of the United States Government. Neither the United States Government nor any agency thereof, nor UChicago Argonne, LLC, nor any of their employees or officers, makes any warranty, express or implied, or assumes any legal liability or responsibility for the accuracy, completeness, or usefulness of any information, apparatus, product, or process disclosed, or represents that its use would not infringe privately owned rights. Reference herein to any specific commercial product, process, or service by trade name, trademark, manufacturer, or otherwise, does not necessarily constitute or imply its endorsement, recommendation, or favoring by the United States Government or any agency thereof. The views and opinions of document authors expressed herein do not necessarily state or reflect those of the United States Government or any agency thereof, Argonne National Laboratory, or UChicago Argonne, LLC.
\end{abstract}




\section{Ocean Thermal Plantships for Production of Ammonia as the Hydrogen Carrier}

by

C.B. Panchal' 1 , P.P. Pandolfini' ${ }^{2}$, and W.H. Kumm ${ }^{3}$

${ }^{1}$ Energy Systems Division, Argonne National Laboratory

${ }^{2}$ The Johns Hopkins University/Applied Physics Laboratory

${ }^{3}$ Arctic Energies, Ltd.

sponsored by

United States Department of Energy,

Assistant Secretary for Energy Efficiency and Renewable Energy,

the Office of the Hydrogen Fuel Cell and Infrastructure Programs,

and the Office of Advanced Water Power.

The design study was conducted by Argonne National Laboratory

under DOEcontract No. DE-AC02-06CH11357.

August 2009 



\section{CONTENTS}

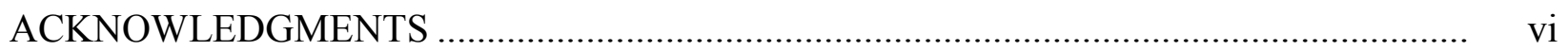

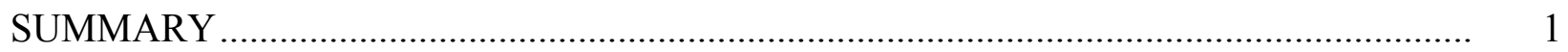

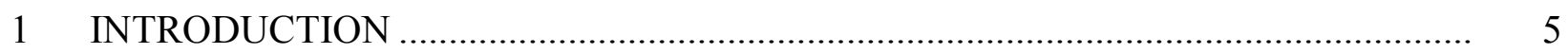

1.1 Ocean Thermal Energy in Impeding Oil Peaking and Fresh Water Supply ........... 5

1.2 DOE Program Goals ......................................................................................... 6

1.3 Expected Outcome and Significance ............................................................... 6

1.4 Scope of the Report.................................................................................................... 7

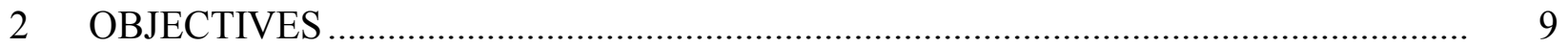

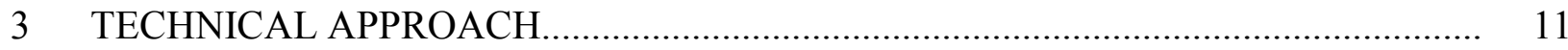

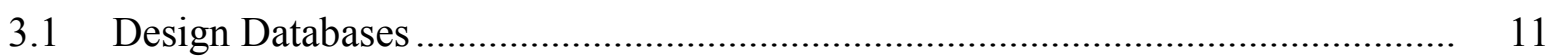

3.2 Conceptual Design of Land-Based Plants.............................................................. 11

3.3 Preliminary Design of Pilot Plantship.................................................................. 13

3.4 Conceptual Design of Commercial-Scale Plantships System............................... 17

3.5 Economic Analysis ........................................................................................ 17

3.5.1 Work-Breakdown Structure (WBS) and Cost Estimates ........................... 17

3.5.2 Economic Analysis Using H2A Program ……………………………...... 19

4 CONCEPTUAL DESIGN OF PLANTSHIPS _......................................................... 21

$4.1 \quad$ Hybrid Cycle Land-Based Plant ........................................................................ 21

4.2 Plantship Design ..................................................................................... 24

4.2.1 Systems Analysis — Heat/Mass/Energy Balances ..................................... 25

4.2.2 Compact Brazed-Aluminum Heat Exchangers .......................................... 29

4.2.3 Plantship Integration .......................................................................... 31

4.3 Solid-State Ammonia Synthesis Process ………............................................. 32

4.4 Hybrid-Cycle Plantship...................................................................................... 35

4.5 Satellite Plantship System................................................................................. 37

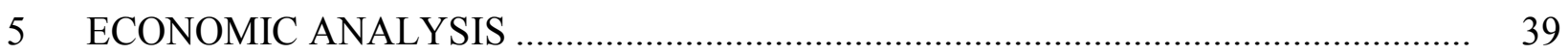

5.1 WBS and Cost Estimates ......................................................................... 40

5.1.1 Plantships for Ammonia Production......................................................... 41

5.1.2 Plantships with Solid-State Ammonia Synthesis Process........................... 43

5.1.3 Plantships with Co-Production of Ammonia and Water............................ 44

5.1.4 Land-Based Plantships for Co-Production of Ammonia and Water........... 45

5.1.5 Production Cost of Desalinated Water....................................................... 45

5.2 H2A Analysis............................................................................................ 48 


\section{CONTENTS (Cont.)}

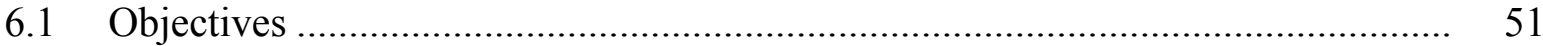

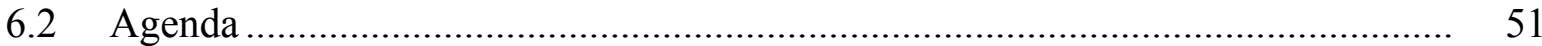

6.3 Project Review ................................................................................... 52

6.4 Open Forum Discussion............................................................................. 53

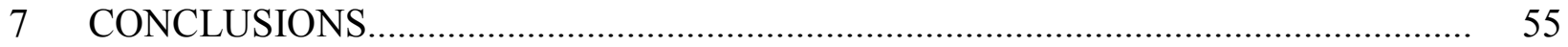

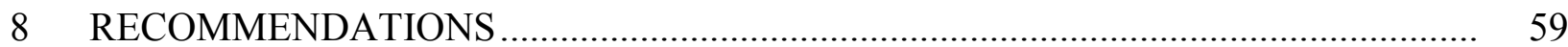

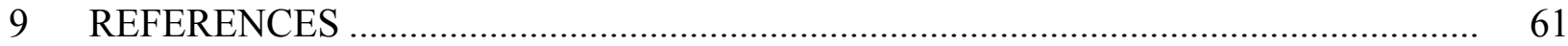

\section{FIGURES}

3.1 Plan View of the 10-MWe Land-Based Ocean Thermal Plant...................................... 12

3.2 Elevation View of the 10-MWe Land-Based Ocean Thermal Plant.............................. 13

3.3 Schematic View of the JHU/APL Ocean Thermal Plantship ...................................... 14

3.4 Layout of the JHU/APL Ocean Thermal Plantship ................................................

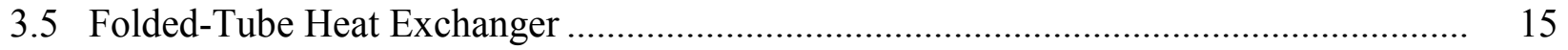

3.6 Process Flow Diagram of the Haber-Bosch Ammonia Synthesis Process ..................... 16

3.7 Equipment Layout of the Ammonia Synthesis Plant ............................................ 16

4.1 Process Flow Diagram of Hybrid Ocean Thermal System ........................................ 22

4.2 Plant Layout of Hybrid-Cycle Ocean Thermal System ........................................... 22

4.3 Seawater System for a Land-based Ocean Thermal Plant ........................................ 23

4.4 Process Flow Diagram of the Two-Stage Power System of the Plantship .................... 26

4.5 Energy Flow Diagram of the Ocean Thermal Plantship ......................................... 27

4.6 Test Unit of JHU/APL Folded-Tube Heat Exchanger (Source: Yung et al. 1981) ......... 30 


\section{FIGURES (Cont.)}

4.7 Test Unit and Elemental Section of Brazed-Aluminum Plate-Fin Heat Exchanger........ 30

4.8 Plantship Layout Showing Overlay of Compact Aluminum Heat Exchangers in the JHU/APL Platform.

4.9 Simplified Process Flow Diagram of the Haber-Bosch Ammonia Synthesis Process ..... 34

4.10 Process Flow Diagram of the NHThree ${ }^{\mathrm{TM}}$ Solid-state Ammonia Synthesis Process....... 34

4.11 Flow Schematic of the Add-on-Hybrid Cycle for Production of Desalinated Water ...... 36

4.12 Schematic Layout of the Hybrid Cycle for Production of Desalinated Water ................ 36

5.1 Chemical Engineering Plant Cost Index and Producer Price Index; Indexed to Reference Year 1981......................................................................................... 40

5.2 Probability Distribution of TIC Results from the Monte Carlo Analysis ....................... 42

\section{TABLES}

3.1 Work-Breakdown Structure of Ocean-Thermal Plants............................................. 18

4.1 Energy and Heat Rate of 10-MW Hybrid Ocean-Thermal Plant.................................. 23

4.2 Process Parameters of 10-MW Hybrid Ocean-Thermal Plant....................................... 24

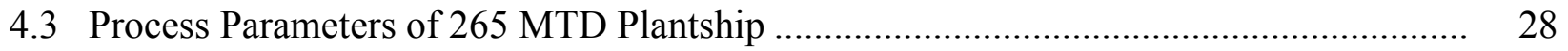

4.4 Energy Balance of 265 MTD Plantship .................................................................... 28

4.5 Process Parameters of the Ocean-Thermal Plantship .............................................. 36

5.1 Total Installed Costs of the $1^{\text {st }}$ and $3^{\text {rd }}$ Generations of Ocean Thermal Plantships.......... 42

5.2 Total Installed Costs of the Ocean Thermal Plantships with Solid-State

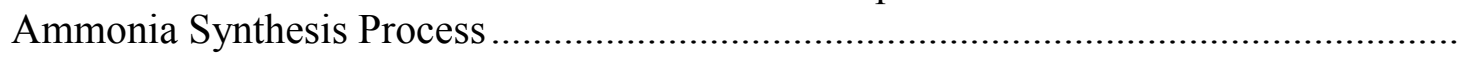

5.3 Total Installed Costs (TIC) of the Ocean Thermal Plantships with Solid-State Ammonia Synthesis Process and Co-Production of Desalinated Water..... 


\section{TABLES (Cont.)}

5.4 Total Installed Costs (TIC) of the Land-Based Ocean Thermal Hybrid-Cycle Plantships

5.5 Energy Required for Desalination and Treatment of Water ................................... 46

5.6 Cost Breakdown of Desalinated Water Production ................................................ 47

5.7 Financial Parameters of the $H 2 A$ Analysis ......................................................... 48

5.8 Cost of Hydrogen: At-Sea Ocean Thermal Plantships ......................................... 49

5.9 Cost of Hydrogen: Land-Based Hybrid-Cycle Ocean Thermal Plantships ................... 50 


\section{ACKNOWLEDGMENTS}

This work was supported by the U.S. department of Energy, Assistant Secretary of Energy Efficiency and Renewable Energy, and the Office of Hydrogen Fuel Cell and Infrastructure Program, and the Office of Advanced Water Power Technologies, under DOE Contract No. DE-AC02-06CH11357. The authors acknowledge Drs. John Holbrook and Jason Gantly of NHThree ${ }^{\mathrm{TM}}$, Inc., for providing details of the solid-state ammonia synthesis process. The valuable contribution of Mr. Traverse Stavac of Cavats Neck Associates in organizing the workshop is acknowledged, and the authors acknowledge the valuable input of the workshop participants. 


\title{
OCEAN THERMAL PLANTSHIPS FOR PRODUCTION OF AMMONIA AS THE HYDROGEN CARRIER
}

\author{
by \\ C.B. Panchal, Peter P. Pandolfini, and William H. Kumm
}

\section{SUMMARY}

Conventional petroleum, natural gas, and coal are the primary sources of energy that have underpinned modern civilization. Their continued availability in the projected quantities required and the impacts of emission of greenhouse gases (GHGs) on the environment are issues at the forefront of world concerns. New primary sources of energy are being sought that would significantly reduce the emissions of GHGs. One such primary source that can help supply energy, water, and fertilizer without GHG emissions is available in the heretofore unexploited thermal gradients of the tropical oceans.

The world's oceans are the largest natural collector and reservoir of solar energy. The potential of ocean energy is limitless for producing base-load electric power or ammonia as the hydrogen carrier and fresh water from seawater. However, until now, ocean energy has been virtually untapped. The general perception is that ocean thermal energy is limited to tropical countries. Therefore, the full potential of at-sea production of (1) ammonia as a hydrogen carrier and (2) desalinated water has not been adequately evaluated. Using ocean thermal plantships for the at-sea co-production of ammonia as a hydrogen carrier and desalinated water offer potential energy, environmental, and economic benefits that support the development of the technology. The introduction of a new widespread solution to our projected energy supply requires lead times of a decade or more. Although continuation of the ocean thermal program from the 1970s would likely have put us in a mitigating position in the early 2000s, we still have a window of opportunity to dedicate some of our conventional energy sources to the development of this renewable energy by the time new sources would be critically needed.

The primary objective of this project is to evaluate the technical and economic viability of ocean thermal plantships for the production of ammonia as the hydrogen carrier. This objective is achieved by completing project tasks that consist of updating the John Hopkins University/Applied Physics Laboratory (JHU/APL) pilot plantship design and extrapolating it to commercial plantships, evaluating a new energy-efficient ammonia synthesis process, evaluating the co-production of desalinated water on plantships, and developing a conceptual design of a satellite plantships system for commercial-scale ammonia production. In addition, an industrial workshop was organized to present the results and develop future goals for commercialization of ocean thermal plantships by 2015 . 
The following goals, arranged in chronological order, were examined at the workshop:

1. Global displacement of petroleum-fuel-based (diesel, fuel oil, naphtha) power generation for freeing up these fuels for transportation, chemical feedstock, and other high-valued uses;

2. At-sea production of desalinated water for regions of critical water shortages;

3. Displacement of carbon-based feed stocks and energy for production of ammonia fertilizers;

4. Development of hydrogen supply to allow economic processing of heavy crude oils and upgrading oil sands;

5. Development of ammonia-fueled distributed energy to displace natural-gasfueled power generation to free up natural gas for higher-value uses and the mitigation of issues associated with imported liquefied natural gas (LNG); and

6. Use of ammonia as a hydrogen carrier for transportation.

The major conclusions derived from this design study are as follows:

- The basic design of the JHU/APL pilot plantship can be scaled to commercial level for at-sea production of ammonia, and compact aluminum heat exchangers significantly improve the technical and economic viability of plantships.

- The solid-state ammonia synthesis process increases the production rate by more than $25 \%$ and capital costs are lower, as compared to the commercial Haber-Bosch process.

- Co-production of desalinated water makes the ocean thermal technology economically viable in the near future.

- Modular power systems, employing compact brazed-aluminum heat exchangers, reduce the technical risk significantly and maintain high plant availability.

- The cost of ammonia production would be $\$ 710 /$ metric ton with this plantship design; however, this study evaluated improved plantship design and coproduction of desalinated water that would significantly reduce the cost of producing ammonia.

- Two specific developments are required to achieve the renewable-energy cost goal: (1) energy-efficient solid-state ammonia synthesis process and (2) integrated hybrid-cycle plantships for co-production of desalinated water. 
- Satellite plantships systems will further reduce production costs because atsea ammonia production plants will be scaled up to 2,000-3,000 metric ton per day (MTD), which is commercial-scale production.

To commercialize ocean thermal plantships by 2015, the following developments should be pursued with high priority:

- At-sea ocean thermal plantships with an integrated hybrid cycle should be developed.

- Significant progress has been made in the application of aluminum heat exchangers to the ocean thermal power system. However, there are salient design and fabrication issues that should be resolved to reduce the technical risk associated with aluminum heat exchangers to achieve a service life of 20 years and beyond.

- The petroleum industry has made significant developments in designing and deploying offshore platforms. Such developments should be incorporated into the design and deployment of ocean thermal plantship platforms.

- A solid-state ammonia synthesis process should be developed for ocean thermal plantships.

- Ammonia as fertilizer is being transported across the world's oceans and shipped to the marketplace in the continental United States. However, the logistics of transporting and storing large quantities of ammonia as the hydrogen carrier should be analyzed.

- A specific scenario of supplying hydrogen and desalinated water to oil refineries in the Gulf of Mexico coastal states by using ocean thermal plantships should be analyzed. Hydrogen will be used to produce cleaner transportation fuels from heavy crude oils. Desalinated water will alleviate the local water-supply problem of industrial applications in that region. 


\section{INTRODUCTION}

\subsection{OCEAN THERMAL ENERGY IN IMPEDING OIL PEAKING AND FRESH WATER SUPPLY}

In the past century, the hydrocarbons supplied by distilled petroleum and natural gas have established an advanced technological society. The use of these products from primary sources (i.e., crude oil and natural gas wells) has allowed the development of ubiquitous and high-speed transportation systems; the extraction and distribution of potable water supplies; and, through the widespread use of ammonia fertilizers derived from natural gas, the increased production of food. The increased population of our planet depends on the continued extraction and use of these large, but finite, petroleum resources.

As long as 50 years ago, Hubbert (1956) conducted an analysis to project the limits on the continued availability of petroleum. Although subsequent opinions differ on the timing, the finite nature of conventional petroleum and natural gas supplies is a subject of vigorous debate ${ }^{1}$. Many analysts foresee the peaking ${ }^{2}$ of conventional petroleum early in the $21^{\text {st }}$ Century.

The availability of potable water to grow and support civilizations is also an emerging issue (DOE Report to Congress 2006). Ultimately, tied up with the availability of abundant energy and abundant potable water is the capacity to produce sufficient food. The "Green Revolution" is supported by the availability of petroleum products and water.

Conventional petroleum is the primary source of energy that has underpinned modern civilization. Its continued availability in the projected quantities required is questioned (Simmons 2005). New primary sources of energy are sought. One such primary source that can contribute to supplying energy, water, and fertilizer is available in the heretofore unexploited thermal gradients of the tropical oceans.

The world's oceans are the largest natural collector and reservoir of solar energy. The potential of ocean energy is limitless for producing base-load electric power or hydrogen and fresh water from seawater. However, until now, ocean energy has been virtually untapped. The general perception is that ocean energy cannot be cost-effective in comparison with conventional energy sources and is limited to tropical countries. Therefore, the full potential of at-sea production of (1) ammonia as an energy carrier and (2) desalinated water has not been adequately evaluated. In a major joint initiative in the 1970s and 1980s, leading industrial organizations and the federal Ocean Thermal Energy Program advanced the technology close to

\footnotetext{
1 An Internet search of "Hubbert's Peak" will lead a researcher to the growing body of literature on this subject.

2 By peaking what is meant is the ability to continue the flow of conventional petroleum at sustained annual rate, not the ultimate size of the resource. Conventional petroleum is a term used for natural crude oil that can be readily refined, that has heavy fractions easy to crack into light distillates, and that is low in sulfur and other heavy metal content. Fairly complex relations exist between the known conventional petroleum reservoirs, the discovery of new reservoirs, the exploitation of these known resources, and the projected availability of conventional petroleum. Non-conventional petroleum (e.g., oil sands) requires more difficult energy-consuming and water-consuming processing, especially in enhancement with hydrogen. A new primary energy source would make continued exploitation of non-conventional petroleum resources possible.
} 
commercialization. However, because of low energy costs - especially for petroleum products and natural gas $^{3}$ - ocean thermal energy technology was not commercialized. Using ocean thermal plantships for the at-sea co-production of ammonia as a hydrogen carrier and desalinated water offers potential energy, environmental, and economic benefits that support the development of the technology.

The introduction of a new widespread solution to our projected energy supply requires lead times of a decade or more (Hirsch 2005). Although continuation of the ocean thermal program from the 1970s would likely have put us in a mitigating position in the early 2000 s, we still have an opportunity to dedicate some of our conventional energy sources to the development of this renewable energy by the time new sources would be critically needed.

\subsection{DOE PROGRAM GOALS}

The U.S. Department of Energy (DOE) Office of Energy Efficiency and Renewable Energy's (EERE's) Hydrogen, Fuel Cells \& Infrastructure Technologies (HFCIT) Program has been pursuing fossil, nuclear, and renewable energy sources to realize the hydrogen economy. The Office of Advanced Water Power is pursuing commercialization of ocean thermal energy. Both of these programs are designed to bring technologies to a point at which technical viability and economics are sufficiently demonstrated for commercialization. The hydrogen target is in alignment with the Hydrogen Fuel Initiative goal of achieving a technology readiness milestone by 2015 and is used to guide hydrogen and fuel cell research and development activities. The National Hydrogen Roadmap highlights the development of advanced renewable energy methods that do not emit carbon dioxide, and the HFCIT Multi-Year R\&D Plan identifies biomass, geothermal, hydro, wind, and solar as renewable energy sources. This project focuses on the ocean thermal energy technology for the production of ammonia as the energy carrier. The Office of Advanced Water Power Technologies is pursuing ocean thermal energy, with a focus on commercialization, by addressing technical and economic barriers.

\subsection{EXPECTED OUTCOME AND SIGNIFICANCE}

The current study is a renewed look at the potential benefits of ocean thermal energy. Avery (1994) has summarized the technology through the mid-1980s. Since that time, many of the components that would comprise an ocean thermal power system have continued to be advanced and proven. The need for energy has expanded to include energy-intensive commodities unique to ocean thermal plants, such as potable water and fertilizer.

This study builds upon the preliminary design of the Johns Hopkins University/Applied Physics Laboratory (JHU/APL) ocean thermal pilot plantship (George and Richards 1980), which was a full-scale engineering design. The work breakdown structure (WBS) used to estimate the cost of that plant and its derivatives is enhanced to include water production systems, and the cost estimates are updated by using standard industrial indices.

\footnotetext{
3 Many of the last known large conventional petroleum reservoirs were brought into production in the late $20^{\text {th }}$
} Century. All of these reservoirs are exhibiting peaking in the early $21^{\text {st }}$ Century (Simmons 2005) 
Considering the potential benefits of at-sea ocean thermal plantships, the impact of this technology on non-carbon-based energy will be quite significant. This project provides the technical and economical bases of achieving the HFCIT cost goals by 2015, as identified in the R\&D Multi-Year Plan and commercialization goal of the Office of Advanced Water Power Technologies. With expanding energy production from natural gas to meet ever-increasing energy demands and $\mathrm{CO}_{2}$ emission limits, market penetration of ammonia fuel cells for distributed power generation can be developed rapidly.

Ocean thermal plants offer an attractive solution to the DOE's Energy-Water Nexus (DOE Report to Congress 2006) objective by co-producing desalinated water. Not only would ocean thermal plants be a large, sustainable primary energy resource, but a direct source of potable water would also be made available. The co-production of desalinated water for regions with high water costs (such as southern California and Florida) would significantly accelerate market penetration for early commercialization of ocean thermal plantships.

This project also suggests a synergetic approach of producing hydrogen and desalinated water in the Gulf of Mexico and supplying these two precious commodities to refineries in that region. The refining capacity of about 6 million barrels per day in this region represents $\sim 40 \%$ of U.S. refining capacity. Hydrogen could be transported through gas pipelines from offshore platforms or as a compressed gas, and desalinated water could be transported by tankers. Hydrogen from renewable ocean thermal energy would then allow refineries to process heavy crude oils by using sustainable hydrogen from non-carbon renewable energy sources. This will reduce the effective carbon footprint of petroleum fuel and products.

\subsection{SCOPE OF THE REPORT}

This project started in FY2006 with limited funding and was completed in FY2007. Argonne National Laboratory (Argonne), JHU/APL, and Arctic Energies, Ltd. (AEL), worked on this project. The scope of project work was to update the economics of ocean thermal plantships on the basis of the previous design studies and to evaluate potential improvements of the technology for making ammonia, as the energy carrier, cost competitive with other renewable energy technologies. This report documents the design data from previous studies and the updated cost estimates and results of the updated design study. The results and analyses are presented according to the five tasks (listed in Section 2) of this project. One of the tasks was to organize a workshop for an industrial review of this project's results and seek input for a plan forward. This report presents the summary of the workshop and tangible goals developed for commercializing ocean thermal plantships. An internal report was submitted to the DOE's Office of HFCIT, and the final report is released with the support of the Office of the Advanced Water Power Technologies. 


\section{OBJECTIVES}

The two primary objectives of this project are to:

1. Establish the technical and economic viability of at-sea ocean thermal plantships for the production of ammonia as the hydrogen carrier so that the economics of this technology may be compared with the economics of other technologies pursued for the production and delivery of hydrogen by using renewable energy to meet the HFCIT hydrogen cost goal of \$2-3/gge (delivered, untaxed, $2005 \$$ by 2015) and

2. Evaluate the economic impact of co-producing ammonia and desalinated water.

The project focused on the economics of the at-sea ocean thermal plantship for the production of ammonia and its delivery to California and the Gulf of Mexico Coastal States via commercial tankers.

These two objectives were achieved by undertaking the following tasks:

Task 1: Updated systems and economic analyses of ocean thermal plantships. This task included compiling the design and cost databases from the previous design studies, which include the preliminary design of the JHU/APL pilot plantship, Argonne's conceptual design of small plants, and conceptual designs of DOE-supported 40-MWe pilot plants. The cost estimates in these design studies were updated to $2005 \$$, which is the reference year used to compare different hydrogen technologies. The ocean thermal process design models were updated with new performance data and for co-production of desalinated water.

Task 2: Improved design of the plantship with compact aluminum heat exchangers. In a conceptual design, the plantship was furnished with compact aluminum heat exchangers, and the system analysis was performed for an improved plantship design with a nominal ammonia production capacity of 265 metric tons per day (MTD).

Task 3: Conceptual design of commercial-scale ocean thermal plantships. This task focused on the design concept of commercial-scale ( 2,600 MTD ammonia) plantship systems, which consist of multiple individual ocean thermal plants providing power to a centralized floating-island platform. The ammonia synthesis plant is installed on the central platform, as is the supporting engineering services.

Task 4: Work breakdown structure (WBS), cost estimates, and economic analysis. A detailed WBS was adapted, itemized cost estimates for major components and subsystems were developed, and an economic analysis was performed by using the DOE's $\boldsymbol{H} \boldsymbol{2} \boldsymbol{A}$ model.

Task 5: Workshop on ocean thermal plantships. The purpose of this workshop was to

present results from the technical and economic analyses of ocean thermal plantships for the 
production of ammonia as the hydrogen carrier, with and without co-production of desalinated water. Key research, business, industrial, and promotional organizations participated in the workshop. The outcome of the workshop provided guidelines for a path forward to the commercialization of ocean thermal plantships. 


\section{TECHNICAL APPROACH}

\subsection{DESIGN DATABASES}

This project focused on establishing the technical and economic viability of ocean thermal plantships for ammonia production on the basis of previous design studies and economic analyses. Therefore, it was important to establish reliable databases from which further improvements can be developed. In a joint project with industrial partners, APL/JHU designed a moored or grazing ocean thermal pilot plantship for the production of ammonia (George and Richards 1980). This design was a nominal 40-MW pilot-sized plant to be used to establish the production techniques for 100-MWe plantships. Subsequent tests of the nested serpentine type heat exchangers ("folded-tubes") indicated that the design used in the JHU/APL pilot plant would produce $46 \mathrm{MW}$, or about 15\% more net power (Pandolfini et al. 1980, 1981; Dugger et al. 1981). The design was further optimized, and cost estimates were later revised (Avery 1988; Avery and $\mathrm{Wu}$ 1994). This preliminary pilot plantship design provided the baseline design and cost data for the current project. This plantship design used low-cost folded-tube heat exchangers, which occupy a large amount of space on the plantship. The design capacity of the plantship was 108 MTD of ammonia production for the nominal 40 MWe of electric power.

Argonne performed design studies of 10-MWe systems to evaluate the technical and economic viability of small land-based ocean thermal plants for the island market (Stevens et al. 1984; Panchal and Bell 1987; and Rabas et al. 1990). A site on the island of Hawaii was selected for a land-based plant (with and without co-production of water), and preliminary cost estimates were developed on the basis of a detailed WBS. Different heat exchanger designs were considered, including compact brazed-aluminum plate-fin heat exchangers and stainless-steel plate heat exchangers. A validated cost algorithm was developed for these heat exchangers on the basis of input from manufacturers. The Argonne design studies provided the baseline design for 10-MWe power modules, which was incorporated into the plantship in the current design study. The advanced brazed-aluminum heat exchangers were incorporated into the revised design, resulting in a significant increase in the plantship's ammonia production capacity without significant design changes to the platform and seawater systems.

\subsection{CONCEPTUAL DESIGN OF LAND-BASED PLANTS}

Argonne analyzed the technical and economic viability of 10-MWe land-based ocean thermal plants for the island market. These studies covered the following three system variants:

1. Single-stage power system:

a. Shell-and-tube heat exchangers,

b. Stainless-steel plate heat exchangers, and

c. Brazed-aluminum heat exchangers;

2. Two-stage power system using brazed-aluminum heat exchangers; and

3. Integrated hybrid-cycle power system for co-production of power and desalinated water using brazed-aluminum heat exchangers. 
The land-based plants require relatively long cold-water pipes; therefore, these design studies focused on minimizing the cold-water flow rates to reduce the cost of the seawater system. Application of high-performance modular heat exchangers was essential for achieving the technical and economic viability of land-based plants, and the brazed-aluminum heat exchanger was shown to be an ideal candidate. In these design studies, arrangement of power system components was developed as a cost-effective deployment method for remote island sites. Figures 3.1 and 3.2, derived from Argonne's design study (Stevens et al. 1984), show plan and elevation views of the 10-MWe power system using brazed-aluminum heat exchangers. As shown in Figure 3.1, the footprint of the 10 MWe plant is $30 \times 33 \mathrm{~m}$.

These studies systematically showed improved design and economic viability of landbased ocean thermal plants using non-conventional heat exchangers as compared to conventional shell-and-tube heat exchangers. Information from the Argonne's design studies is used in the present project, namely: (1) the performance and cost data of brazed-aluminum heat exchangers and (2) the hybrid cycle design for co-production of power and desalinated water.

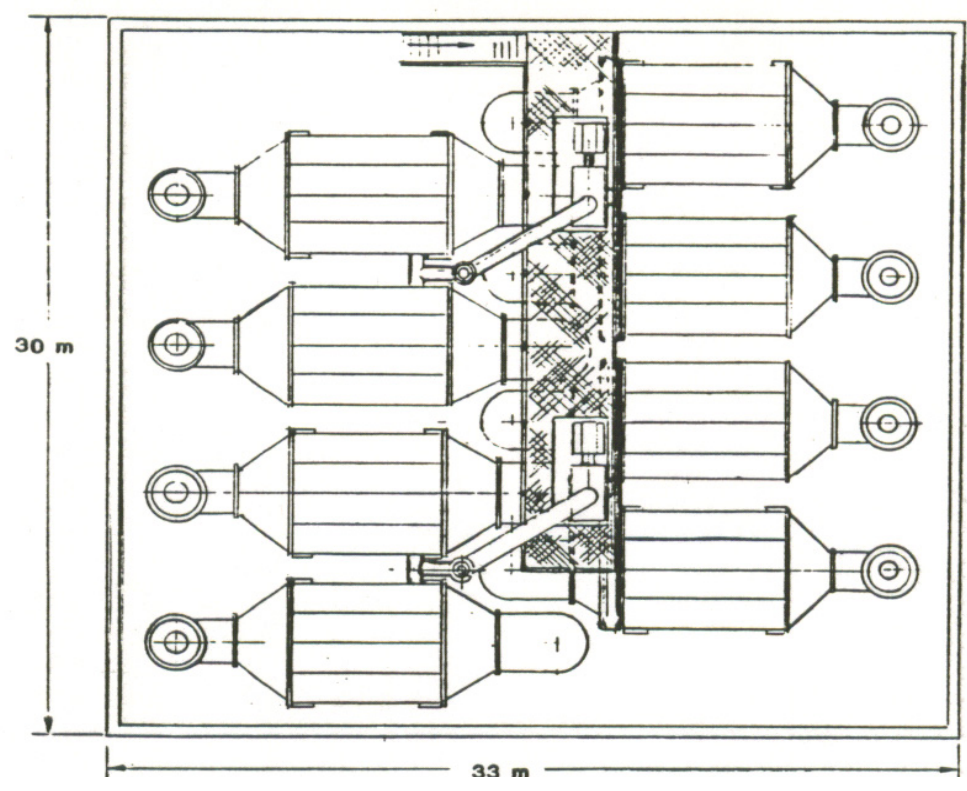

FIGURE 3.1 Plan View of the 10-MWe Land-Based Ocean Thermal Plant 


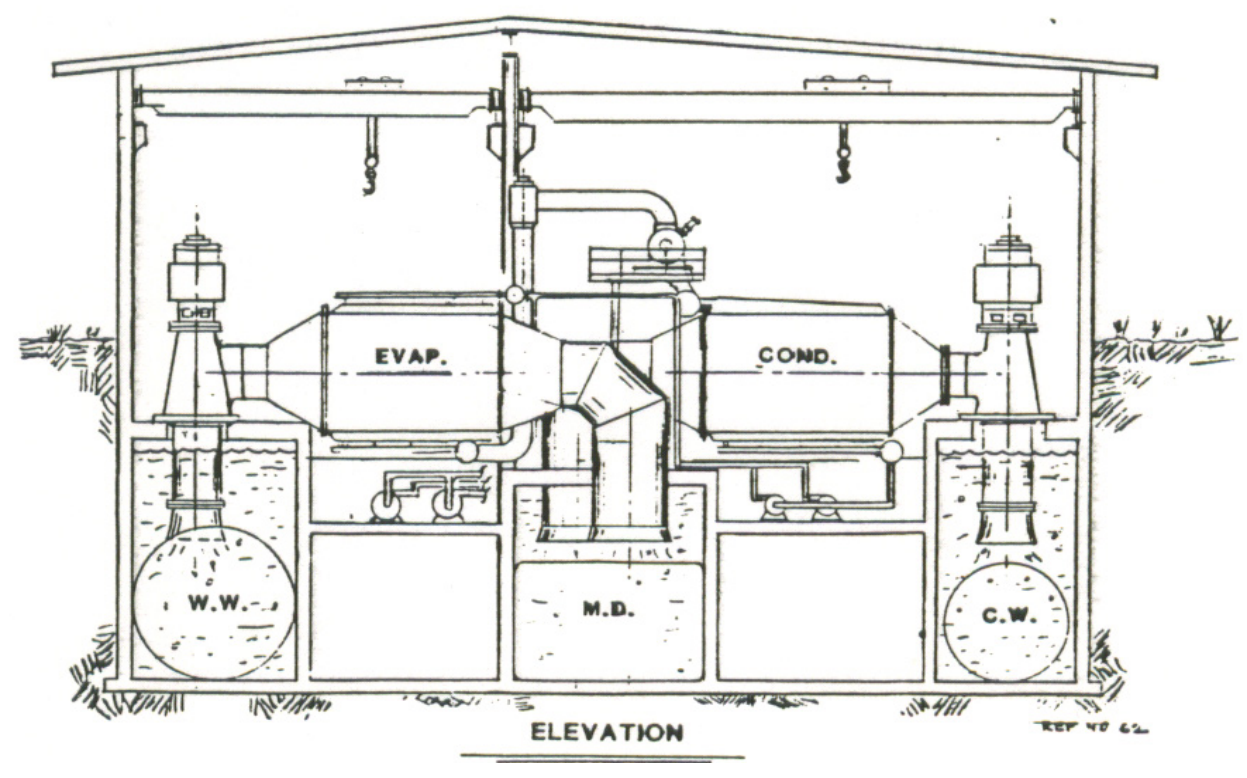

FIGURE 3.2 Elevation View of the 10-MWe Land-Based Ocean Thermal Plant

\subsection{PRELIMINARY DESIGN OF PILOT PLANTSHIP}

The JHU/APL ocean thermal plantship has nominal power-generating capacity of $40 \mathrm{MWe}$, which is used to produce $104 \mathrm{MTD}$ of ammonia. This plantship was intended to be a pilot plant for testing different power system components. JHU/APL was the project manager, and the design team consisted of the following industrial partners:

- ABAM Engineers, Inc. — for the hull and cold water pipe;

- LR Glosten and Associates, Inc. - for the naval architecture and marine engineering;

- Tokala Offshore, Inc. — for the construction and deployment;

- Seward Associates - for the electric design;

- JR Paling, Inc. - for the cold water pipe dynamics; and

- The Trane Co. - for the heat exchanger fabrication.

Figures 3.3 and 3.4 (George and Richards 1980) show a schematic view of the plantship and the equipment layout, respectively. The original ocean thermal plantship design incorporated folded-tube heat exchangers (Figure 3.5). They were less expensive to build; however, they occupied significant space on the plantship. The working fluid flows inside of 76-mm (3-in.) 


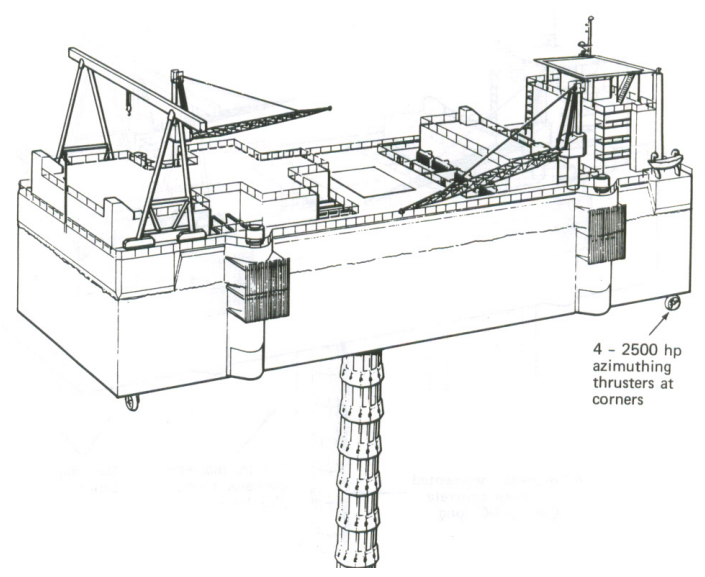

FIGURE 3.3 Schematic View of the JHU/APL Ocean-Thermal Plantship (Source: JHU/APL Report, George and Richards 1980)

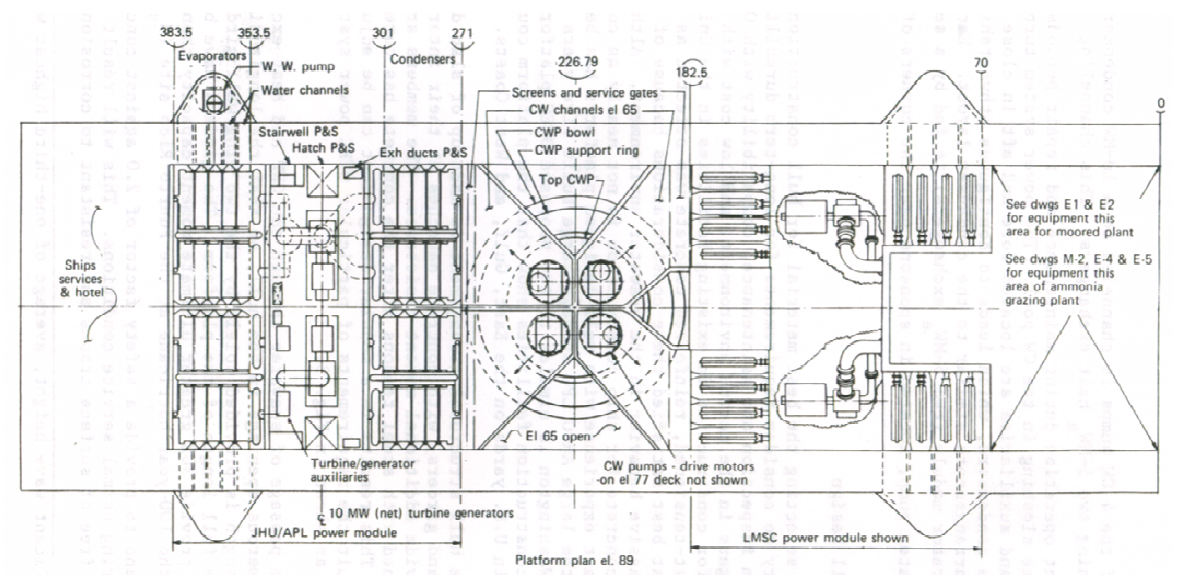

FIGURE 3.4 Layout of the JHU/APL Ocean-Thermal Plantship (Source: JHU/APL Report, George and Richards 1980) 


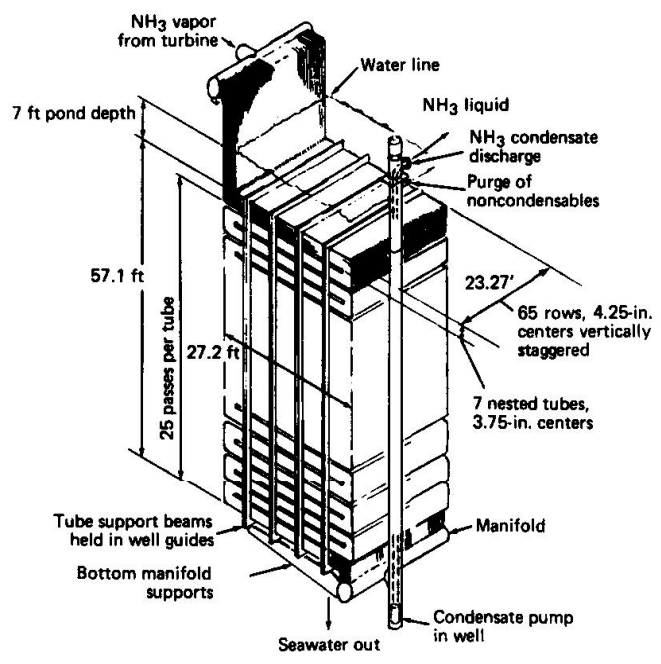

FIGURE 3.5 Folded-Tube Heat Exchanger (Source: JHU/APL Report, George and Richards 1980)

tubes, which are nested in the modules shown in Figure 3.5 (George and Richards 1980). Seawater flows over the nested tube bundle from top to the bottom. The performance of this heat exchanger was validated at the Argonne heat exchanger test facility (Yung et al. 1981)

The on-board power was supplied to GE electrolyzers to generate hydrogen, which was fed to the ammonia synthesis plant. Nitrogen was generated by commercial air-separation process units. A process flow diagram of the ammonia synthesis process is shown in Figure 3.6, and the layout of the on-board ammonia synthesis plant is shown in Figure 3.7 (George and Richards 1980). The Haber-Bosch ammonia synthesis process consists of pressurizing the feed gases of hydrogen and nitrogen to about 90 bars and preheating the gases to a reaction temperature of $500^{\circ} \mathrm{C}$. The process is highly exothermic and requires an effective heat recovery system, as shown in the process diagram. The steam generated in the waste-heat recovery boiler is used to run the refrigeration compressor. 


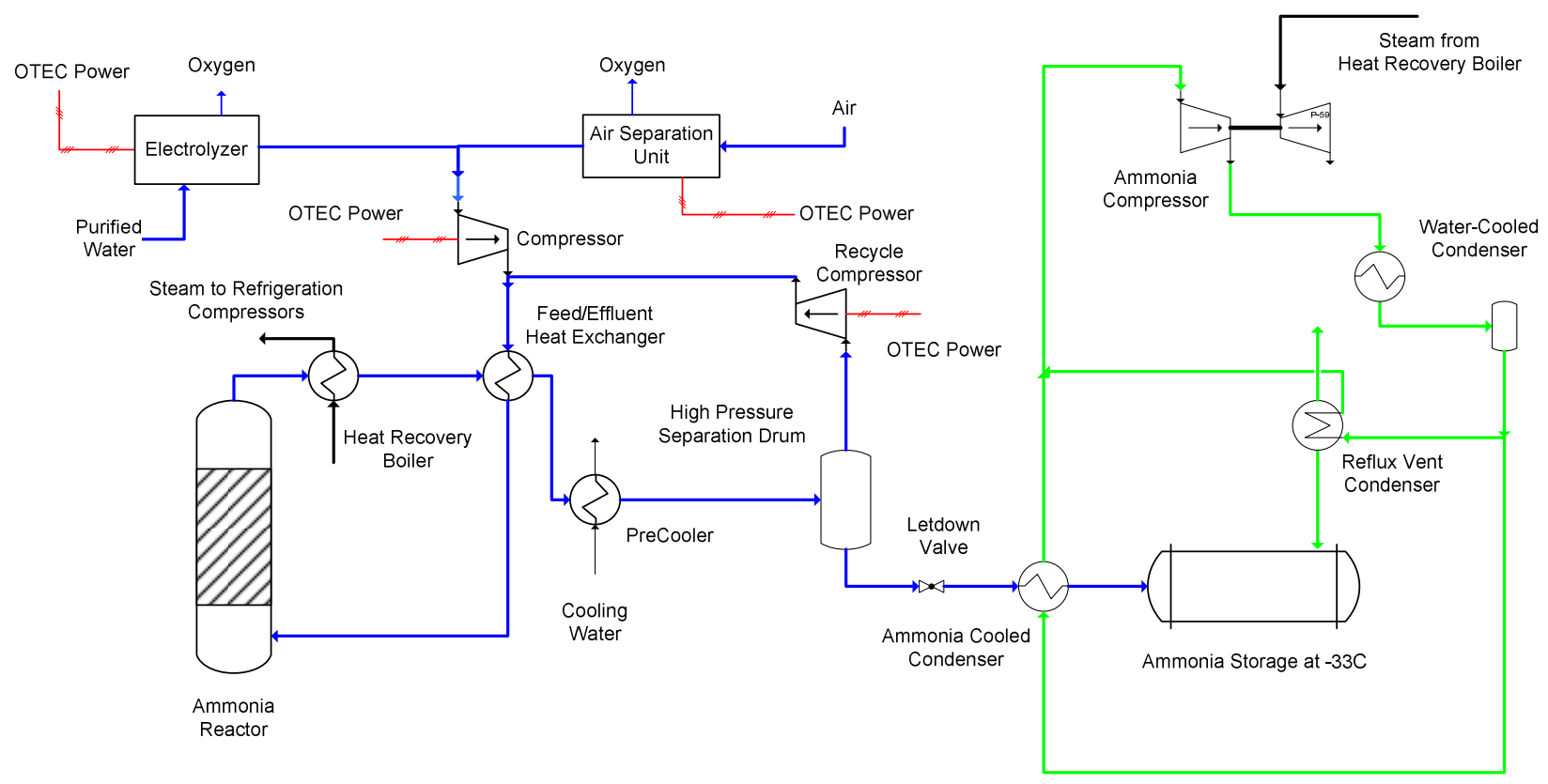

FIGURE 3.6 Process Flow Diagram of the Haber-Bosch Ammonia Synthesis Process
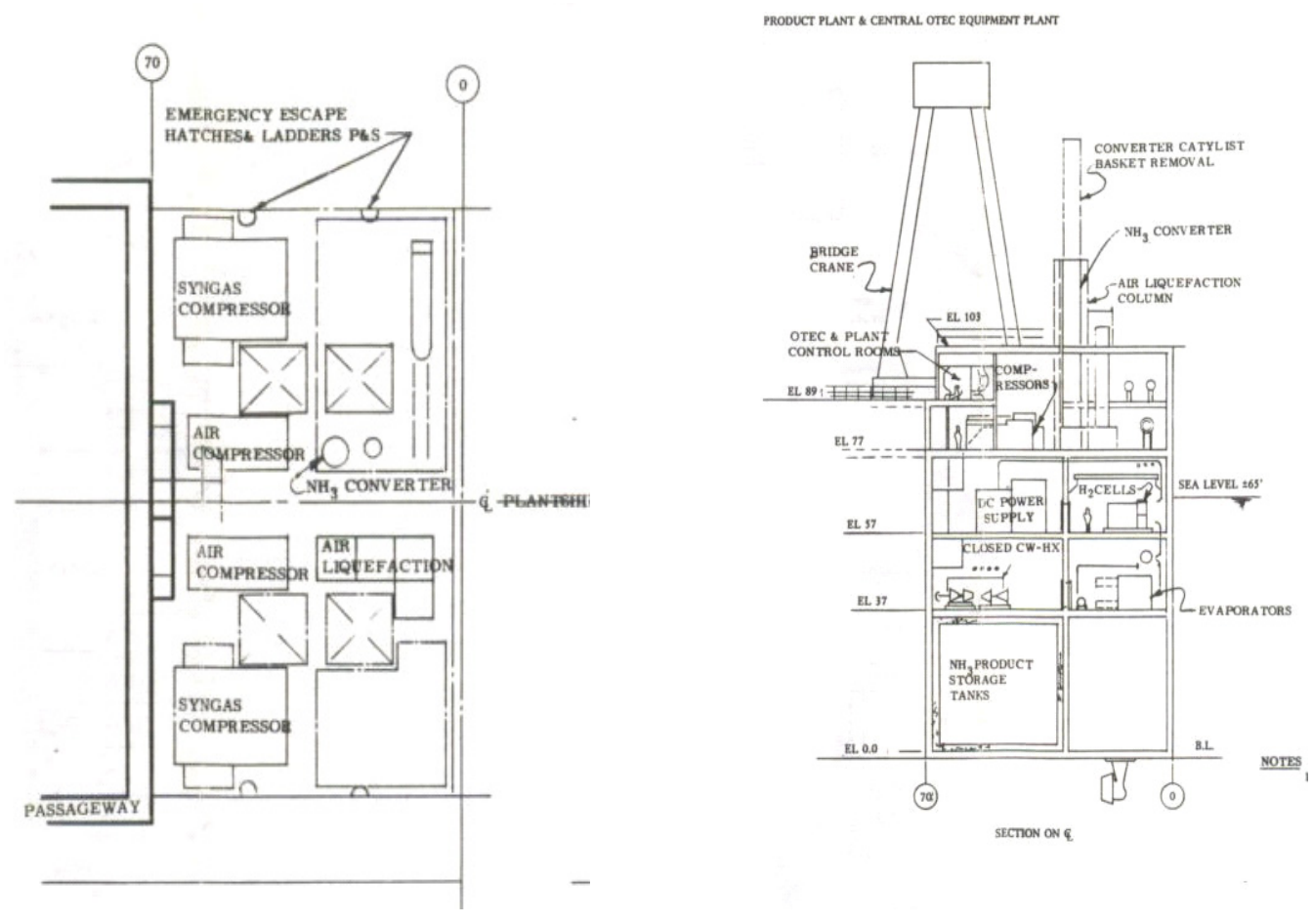

FIGURE 3.7 Equipment Layout of the Ammonia Synthesis Plant (Source: JHU/APL Report, George and Richards 1980) 


\subsection{CONCEPTUAL DESIGN OF COMMERCIAL-SCALE PLANTSHIPS SYSTEM}

A single at-sea plantship with a nominal design capacity of $100 \mathrm{MWe}$ would produce about 260 MTD of ammonia. Individual at-sea ocean thermal plants can be placed apart, within safe operating distances of 10-20 nautical miles. Several of these individual plants can provide the power to a centralized commercial-scale ammonia synthesis plant with a capacity of 1,5003,000 MTD. The concept is similar to offshore petroleum production, processing, and transportation to the market place via underwater pipes or by tankers. A group of 10 plants can be deployed in an area of open ocean containing favorable thermal gradients. Satellite-gathered surface temperature data would be used to locate the most favorable spots and to keep the plant fleet abreast of surface weather conditions. The individual plants in the group would circle a central point and be several miles from each other; the radii of the orbits around a central servicing plant would range from 10 to 20 nautical miles, and not all plants need to be located equidistant from the center. A minimal operating crew would run each plant, with specialized high-cost resources, such as engineers and specialized plant mechanics (residents of the local group), ferried to and from a plantship as needed.

An auxiliary fleet of service ships would run back and forth to the plants to bring supplies, enable crew changes, and transport product to land-based depots. Using ten 100-MWsized plants, the group would be designed for a total capacity of 2,600 MTD of ammonia. In a combined design, some of the units in the group would be dedicated to water production, also in economical amounts compatible with market demands. Water production of 200-500 million liters per day is expected to provide substantial economic benefits.

With the focus on southern California, the commercial-scale plantship system could be deployed 500-1,000 nautical miles southwest of San Diego. In the Gulf of Mexico, the plantship system can be deployed close to Florida and other coastal states. As worldwide use of the ocean thermal resource expands, the groups would be replicated in other parts of the world's oceans.

\subsection{ECONOMIC ANALYSIS}

\subsubsection{Work-Breakdown Structure (WBS) and Cost Estimates}

The WBS has evolved on the basis of design studies of conceptual designs of 100-MWe floating plants in the 1970s, the 40-MWe land-based pilot plant in the 1980s, pilot plantship, and the $10-\mathrm{MWe}$ land-based small ocean thermal plants by various industrial organizations and national laboratories. The WBS consists of four-level work breakdowns and corresponding cost estimates. A basic structure of the three-level WBS is presented in Table 3.1.

The cost estimates of the platform, seawater system, and deployment were derived from the original design of the JHU/APL plantship by applying Chemical Engineering cost indices to convert from $1980 \$$ to $2005 \$$. Costs of brazed-aluminum heat exchangers were determined from a cost algorithm developed by Argonne. Updated cost estimates of the ammonia turbine/generator and sweater pumps were developed on the basis of previous vendor budgetary 
quotes. The cost of the water production subsystem was estimated from known costs of multistage flash (MSF) evaporators. The cost and performance of the electrolyzer was obtained from the reported data of the NorskHydro system (Shinnar and Citro 2007). The cost of the ammonia synthesis plant with pure hydrogen as the feedstock is stated to be about one-third the cost of natural-gas-based ammonia plant (Gosnell 2006). The total installed cost of the natural-gas-based ammonia plant was obtained from a reported cost of a plant in Trinidad (\$268 for a turnkey construction of 1,850 MTD plant, 2000\$).

The uncertainty of estimating costs was evaluated by using the Monte Carlo technique. Crystal Ball ${ }^{\mathrm{TM}}$ v. 4.0, an Excel $^{\mathrm{TM}}$ add-on, was employed for the Monte Carlo analysis. Each element of the WBS was assigned a high, low, and the most likely estimate on the basis of uncertainties in the sources of cost data. A triangular probability distribution between the high, low, and the likely cost estimate was used for the Monte Carlo trials. Each run consisted of 25,000 trails, which produced close to normal distribution of the total installed cost of the plantship. Depending on the cost uncertainty on the high side or low side, the most likely cost estimate may or may not be an average value. Therefore, the most likely total installed costs would not be the sum of the most likely cost of WBS elements. The resulting multiplier to the capital cost was then used in the $\boldsymbol{H} \mathbf{2} \boldsymbol{A}$ analysis.

TABLE 3.1 Work-Breakdown Structure of Ocean-Thermal Plants

\begin{tabular}{|c|c|c|}
\hline 1st Level & & 2nd Level \\
\hline \multirow[t]{2}{*}{ 1.0 General Management } & 1.1 & Design Phase Management \\
\hline & 1.2 & Acquisition, Construction, Deployment Management \\
\hline \multirow{6}{*}{ 2.0 Engineering Design } & 2.1 & Systems Engineering and Design \\
\hline & 2.2 & Structure and Platform \\
\hline & 2.3 & Seawater System \\
\hline & 2.4 & Power System \\
\hline & 2.5 & Ammonia System \\
\hline & 2.6 & Product Transfer System \\
\hline \multirow{6}{*}{ 3.0 Acquisition and Construction } & 3.1 & General Construction Management \& Engineering \\
\hline & 3.2 & Site Preparation and Improvements \\
\hline & 3.3 & Structure and Building \\
\hline & 3.4 & Power System \\
\hline & 3.5 & Platform System Construction \\
\hline & 3.6 & Seawater Pipe System \\
\hline \multirow[t]{3}{*}{ 4.0 Deployment } & 4.1 & Platform \\
\hline & 4.2 & Cold Water Pipe \\
\hline & 4.3 & Mixed Water Return Pipes \\
\hline \multirow[t]{4}{*}{ 5.0 Commissioning } & 5.1 & Permit \& Licensing Requirements \\
\hline & 5.2 & Safety and Operation plan \\
\hline & 5.3 & Start-up Tests \\
\hline & 5.4 & Performance Validation \\
\hline
\end{tabular}




\subsubsection{Economic Analysis Using H2A Program}

The DOE's Excel-based $\boldsymbol{H} \boldsymbol{2} \boldsymbol{A}$ program was used to determine the cost of ammonia, as the energy carrier, at $10 \%$ after tax Internal Rate of Return (IRR). The WBS-based capital and estimated operation and maintenance $(\mathrm{O} \& \mathrm{M})$ costs were included in the $\boldsymbol{H} \mathbf{2} \boldsymbol{A}$. Other economic assumptions and parameters, including the replacement costs, in the $\boldsymbol{H} \mathbf{2} \boldsymbol{A}$ program were used without any change. This study assumed a construction period of two years for the land-based plant and the three years for the floating plantship. 


\section{CONCEPTUAL DESIGN OF PLANTSHIPS}

\subsection{HYBRID CYCLE LAND-BASED PLANT}

This design study focused on the island market, where simultaneous production of power or compressed hydrogen, along with desalinated water, is shown to be competitive at a 10-MW plant size for a fuel price based on $\$ 50 /$ barrel crude oil price and a water price of $\$ 0.9 / \mathrm{m}^{3}$ (Vega 1992). The world's islands, such as Hawaii and Puerto Rico, predominantly use petroleum-liquid fuels (diesel and fuel oil) for power generation.

A preliminary design was carried out for Keahole point on the island of Hawaii on the basis of the previous design study (Panchal and Bell 1987). Figures 4.1 and 4.2 show the process flow diagram (PFD) and the plant layout, respectively. The seawater system for a generic landbased site on an island is shown in Figure 4.3. Cold water is drawn from a depth of 650-1,000 m by using a buoyant Fiberglass Reinforced Plastic (FRP) pipe system. Warm water is drawn from a depth of about 20-50 m. In the shallow-water region, cold, warm, and effluent water pipes are bottom-mounted and held by weight anchors. All pipes are channeled through the land region to the plant with a low-pressure-drop water-distribution system.

Tables 4.1 and 4.2 show energy balance and process parameters of the plant, respectively. Warm seawater at $25.6^{\circ} \mathrm{C}$ is pumped into the flash chamber, where about $0.5 \%$ of the incoming seawater is converted into steam. The low-pressure steam, generated in the flash evaporator, flows to the ammonia evaporator. About $95 \%$ of the steam is condensed in the ammonia evaporator, which is an aluminum plate-fin heat exchanger, assembled by using a brazing technique. The resulting condensate produces desalinated water. The remaining steam and noncondensable gases flow to the vent condenser, which is cooled by boiling ammonia. A relatively inexpensive and thermally effective heat exchanger can be used as the steam condenser/ammonia evaporator because the seawater does not come in contact with the metallic surface. Steam condenses in horizontal channels formed by fins, while ammonia evaporates on vertical channels formed by serrated fins. Liquid ammonia is sprayed over the top surface of the evaporator, and the vapor/liquid mixture exists from the bottom of heat exchanger. The ammonia vapor is separated in a separation drum and flows to the turbine. The ammonia vapor drives the turbine, and the low-pressure ammonia is condensed in a condenser cooled by cold water from the deep ocean at $5.6^{\circ} \mathrm{C}$. Flashing of the warm seawater causes desorption of dissolved gases, which are cooled in the vent condenser and exhausted by using a vacuum-pump system. A high-pressure NorskHydro electrolyzer was considered for hydrogen production. Hydrogen produced at 101 bar can be distributed directly to island's filling stations. The ocean thermal plant would produce hydrogen at a rate of $250 \mathrm{~kg} / \mathrm{h}$, ammonia at $34 \mathrm{MTD}$, and desalinated water at 22.4 million liters per day (mlpd).

The land-based hybrid cycle plants can be designed for low maintenance and operating costs. With proper instrumentation and controls, the plant can be operated by a crew of five with engineering support, as needed. 


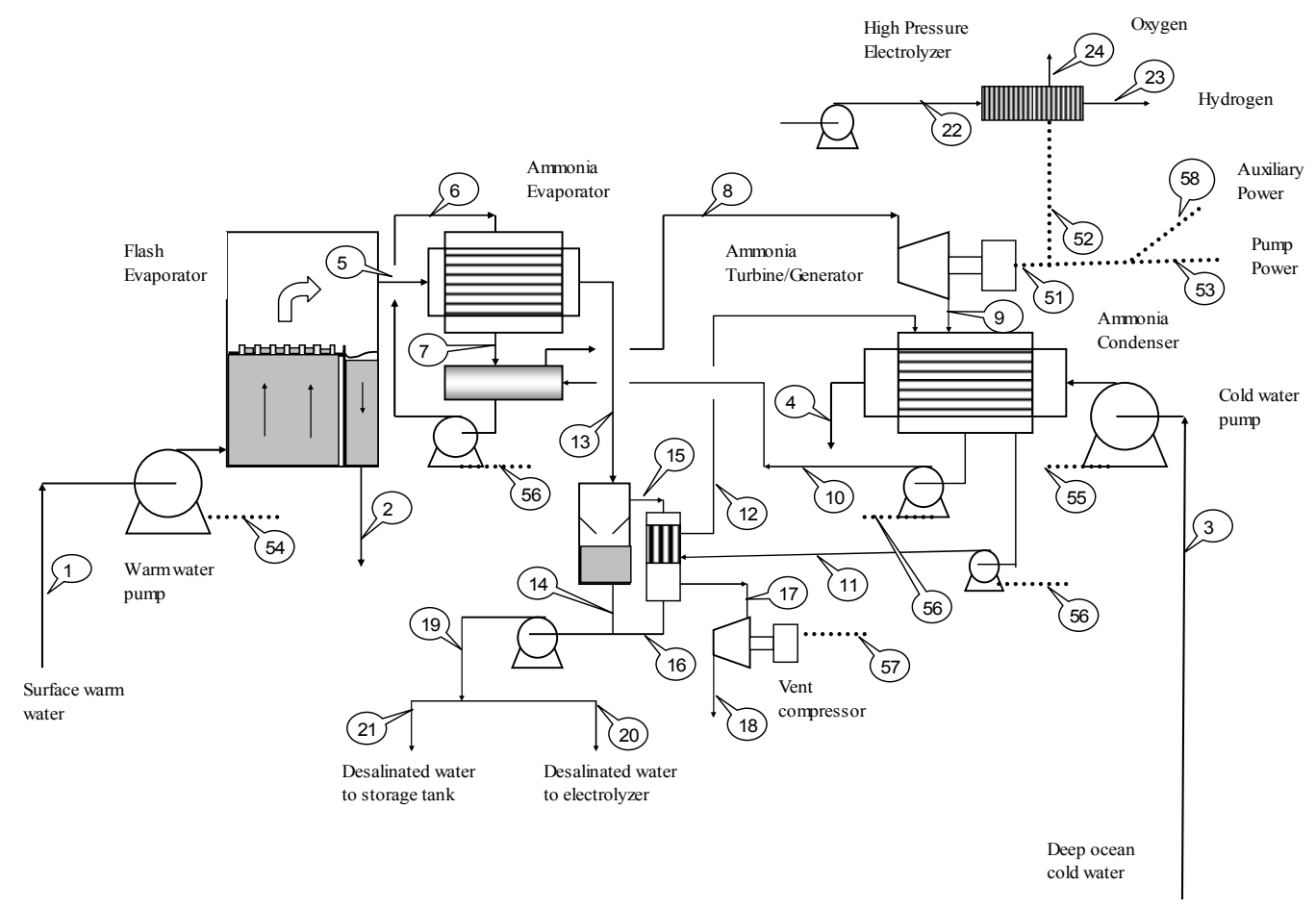

FIGURE 4.1 Process Flow Diagram of Hybrid Ocean-Thermal System

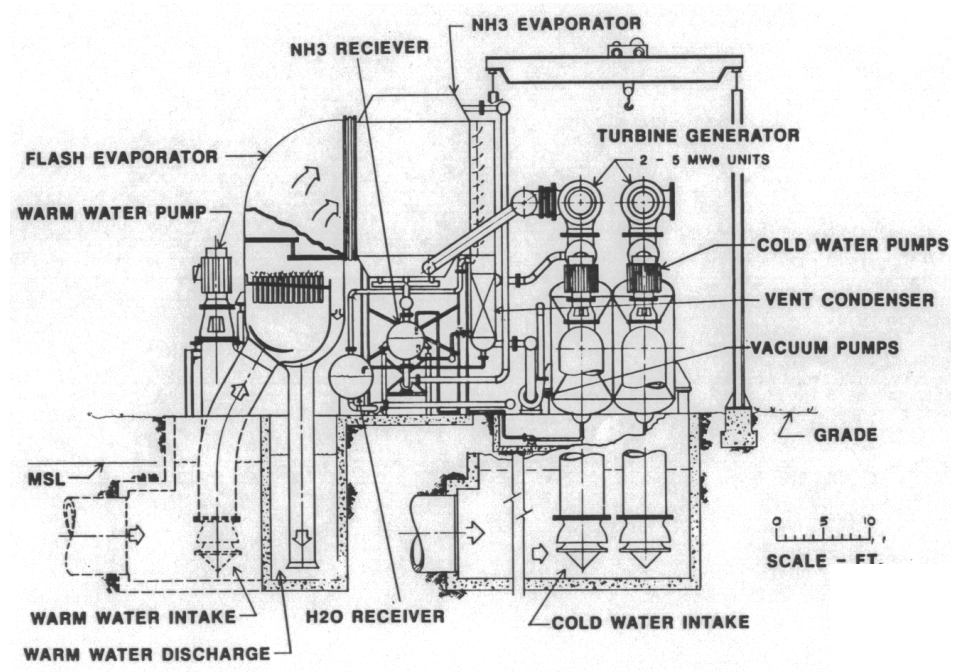

FIGURE 4.2 Plant Layout of Hybrid-Cycle OceanThermal System 


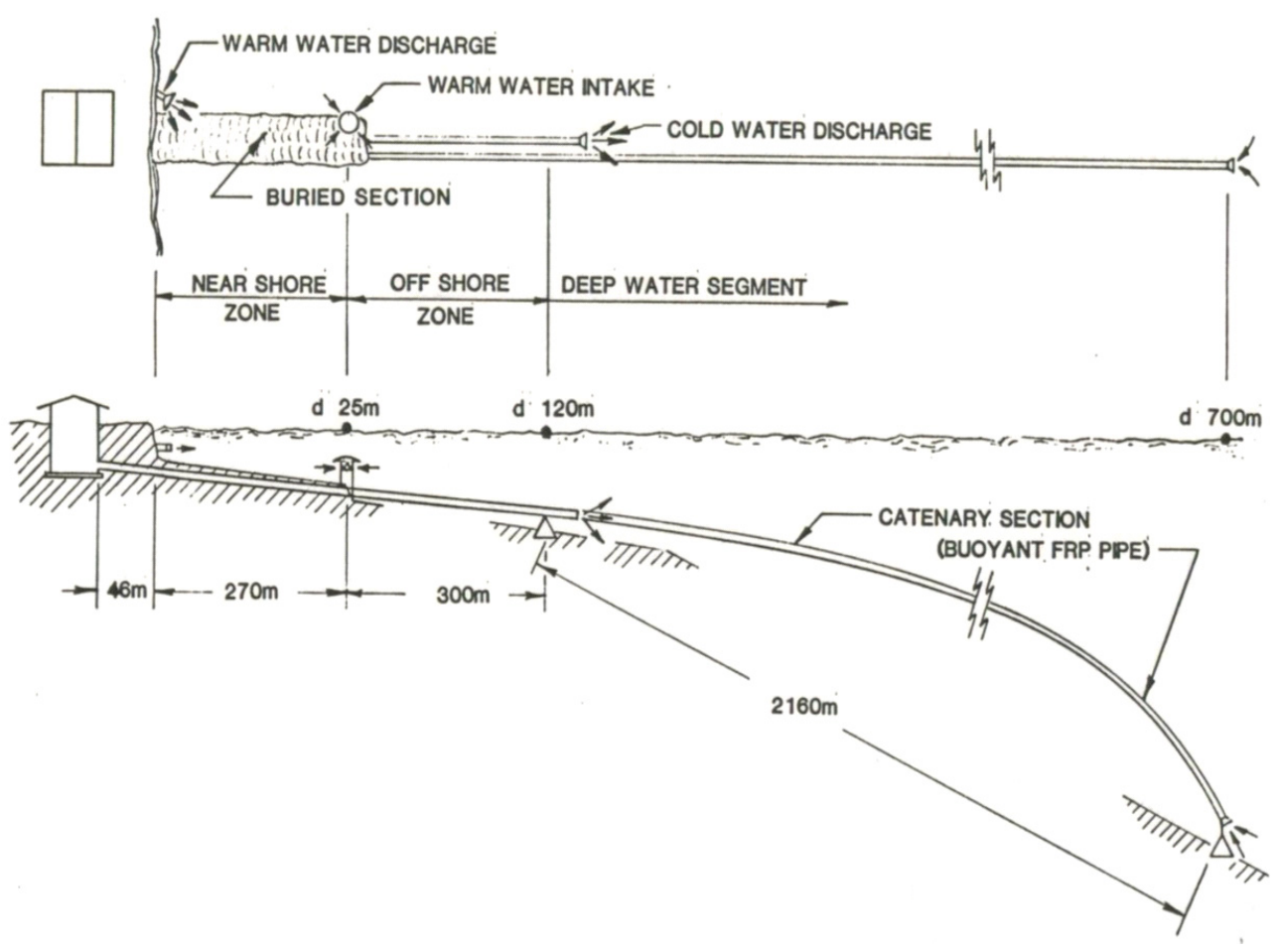

FIGURE 4.3 Seawater System for a Land-Based Ocean-Thermal Plant

TABLE 4.1 Energy and Heat Rate of 10-MW Hybrid Ocean-Thermal Plant

\begin{tabular}{clrr}
\hline $\begin{array}{c}\text { Energy } \\
\text { Stream }\end{array}$ & \multicolumn{1}{c}{ Description } & $\begin{array}{r}\text { Power } \\
(\mathrm{kW})\end{array}$ & $\begin{array}{r}\text { Heat Rate } \\
(\mathrm{MW})\end{array}$ \\
\hline & & 15,307 & \\
51 & Gross power & 10,014 & \\
52 & Net power to electrolyzer & 1,920 & \\
54 & Warm water pumping & 2,550 & \\
55 & Cold water pumping & 327 & \\
56 & Ammonia pumps & 396 & \\
57 & Non-condensable gas exhaust system & 100 & 639 \\
58 & Auxiliary (lighting, controls, etc.) & & 607 \\
61 & Flash evaporator & & 619 \\
62 & Ammonia evaporator/steam condenser & & 30 \\
63 & Ammonia condenser & & \\
64 & Vent condenser & & \\
& & & \\
\end{tabular}


TABLE 4.2 Process Parameters of 10-MW Hybrid Ocean-Thermal Plant

\begin{tabular}{|c|c|c|c|c|}
\hline $\begin{array}{l}\text { Flow } \\
\text { Stream }\end{array}$ & Description & $\begin{array}{c}\text { Temperature } \\
\left({ }^{\circ} \mathrm{C}\right)\end{array}$ & $\begin{array}{c}\text { Pressure } \\
\text { (Bar) }\end{array}$ & $\begin{array}{c}\text { Mass Flow } \\
\left(10^{3} \mathrm{~kg} / \mathrm{h}\right)\end{array}$ \\
\hline 1 & Surface warm water supply & 25.6 & & \\
\hline 2 & Warm water discharge & 21.8 & & \\
\hline 3 & Deep ocean cold water supply & 5.6 & & \\
\hline 4 & Cold water discharge & 10.3 & & \\
\hline 5 & Low-pressure steam & 21.4 & 0.025 & 941 \\
\hline 6 & Ammonia feed to evaporator & 18.3 & 8.5 & \\
\hline 7 & Two-phase ammonia from evaporator & 19.7 & 8.4 & \\
\hline 8 & Ammonia vapor to turbine & 19.7 & 8.4 & 1786 \\
\hline 9 & Ammonia vapor exhaust from turbine & 10.8 & 6.2 & 1786 \\
\hline 10 & Condensate & 10.8 & 6.2 & 1786 \\
\hline 11 & Ammonia feed to vent condenser & 10.8 & 6.2 & \\
\hline 12 & Ammonia vapor from vent condenser & 10.8 & 6.2 & \\
\hline 13 & Condensed water plus non-condensable gases & 20.3 & & 941 \\
\hline 14 & Desalinated water & 20.3 & & 891 \\
\hline 15 & Steam plus non-condensable gases & 20.3 & & 49.5 \\
\hline 16 & Desalinated water from vent condenser & 10.9 & & 44.9 \\
\hline 17 & Steam plus non-condensable gases & 10.9 & & 4.2 \\
\hline 18 & Exhaust non-condensable gases & 22.0 & & 4.2 \\
\hline 19 & Desalinated water & 19.8 & & 936 \\
\hline 20 & Water for electrolyzer & 19.8 & & 2.3 \\
\hline 21 & Net desalinated water production & 19.8 & & 934 \\
\hline 22 & Water feed to electrolyzer & 19.8 & 101.6 & 2.3 \\
\hline 23 & Hydrogen production & & 101.6 & 0.25 \\
\hline 24 & Oxygen production & & & 2.0 \\
\hline
\end{tabular}

\subsection{PLANTSHIP DESIGN}

The basic update of the JHU/APL pilot plantship consists of the following design changes:

- Redesign of the plantship by incorporating aluminum plate-fin heat exchangers, an alternative electrolyzer for hydrogen production, and an ammonia synthesis plant, without modification of the basic structure of the platform;

- Modification of the platform design is assumed for enhancing the seaworthiness of the original platform by keeping the internal structure same as in the original design;

- Update of the WBS to reflect design changes; 
- Update of the platform costs to $2005 \$$ by using the Chemical Engineering Plant Cost Index (CEPCI);

- Use of new cost estimates for the power system: heat exchangers, turbine/generator, pumps, electrolyzer for hydrogen production, and ammonia synthesis plant;

- Conversion of the cold-water pipe from concrete to fiberglass-reinforced plastic (RFP); and

- Incorporation of the co-production of desalinated water by using the hybridcycle power system.

\subsubsection{Systems Analysis - Heat/Mass/Energy Balances}

A two-stage power system is employed to maximize the power generation for the given size of cold-water pipe and the ocean platform. The process flow diagram (PFD; see Figure 4.4) shows that the two heat exchangers are connected in series for the seawater flow; however, the ammonia power system is divided into high-pressure and low-pressure power systems. This twostage power system has higher thermal-conversion efficiency and, therefore, reduces seawater flow rates. A cost-effective two-stage power system is possible with the use of high-performance aluminum-brazed heat exchangers. They have high thermal effectiveness to maintain a lower temperature difference between the seawater and boiling/condensing of the working fluid ammonia. Furthermore, their modular design provides cost-effective integration with the floating ocean platform.

Tables 4.3 and 4.4 present process parameters and energy balances, respectively. A detailed energy flow diagram is presented in Figure 4.5. By using these compact heat exchangers in this manner, the redesigned plantship would produce $130 \mathrm{MW}$ of gross power by using the same platform and same size of cold-water pipe as in the JHU/APL pilot plantship.

The high-pressure NorskHydro electrolyzer has a conversion efficiency of $48 \mathrm{kWh} / \mathrm{kg}$ and produces $1,948 \mathrm{~kg} / \mathrm{h}$ of hydrogen from $93.5 \mathrm{MW}$ of input power to the electrolyzer. This would produce 265 MTD of ammonia by using a conventional Haber-Bosch ammonia synthesis process. The synthesis process is an exothermic reaction, and the heat of reaction is used to generate $1,602 \mathrm{hp}$ in a steam plant, of which $967 \mathrm{hp}$ is used in the refrigeration system at $-33^{\circ} \mathrm{C}$ for refrigeration and storage of ammonia. The remaining $385 \mathrm{hp}$ is used in the closed-loop chilling load that is required for the air liquefaction process and intercoolers of SynGas compressors. Further improvements of heat integration in the conventional ammonia synthesis process would increase the energy efficiency and increase the production rate by about $5 \%$. 


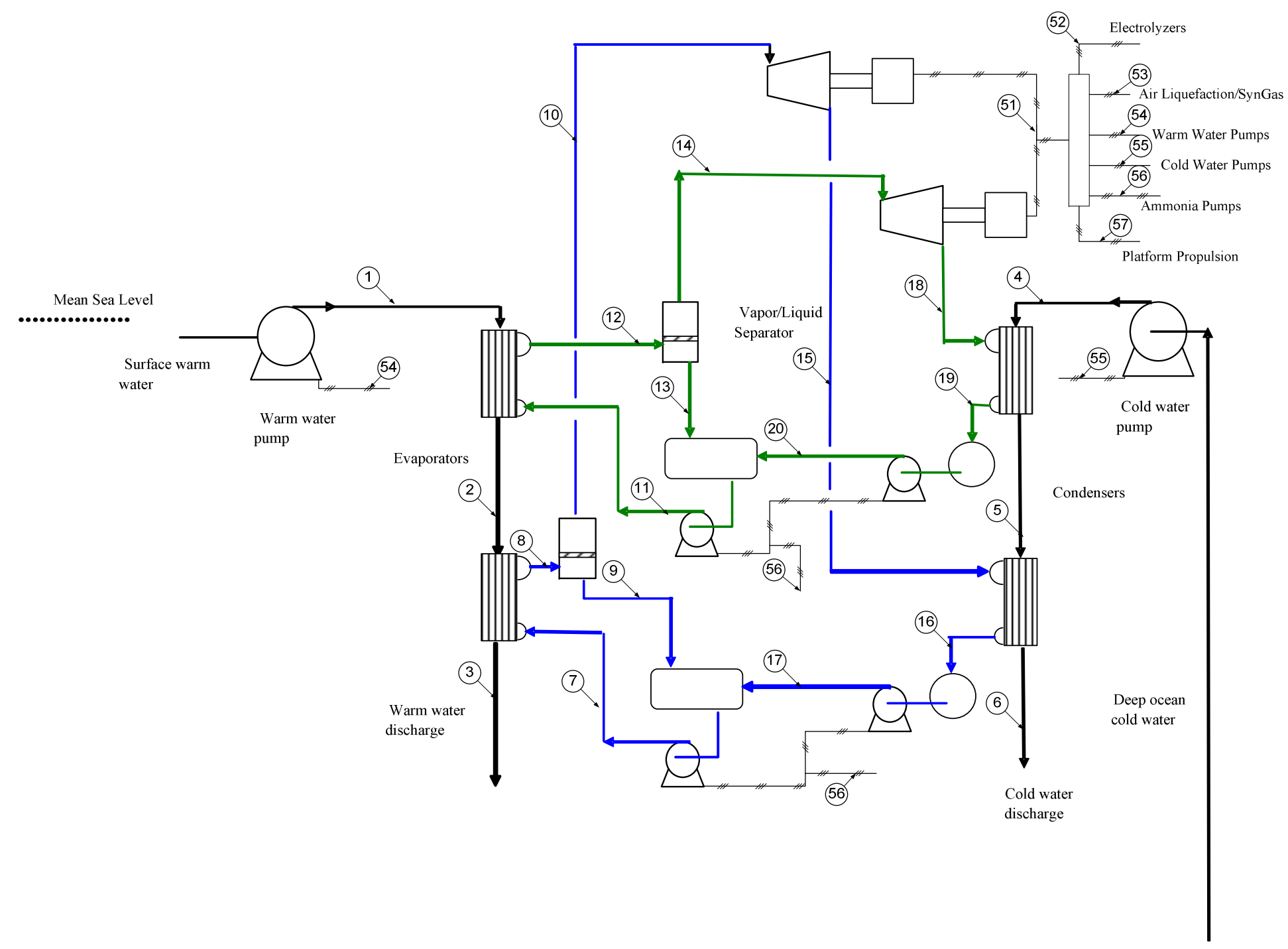




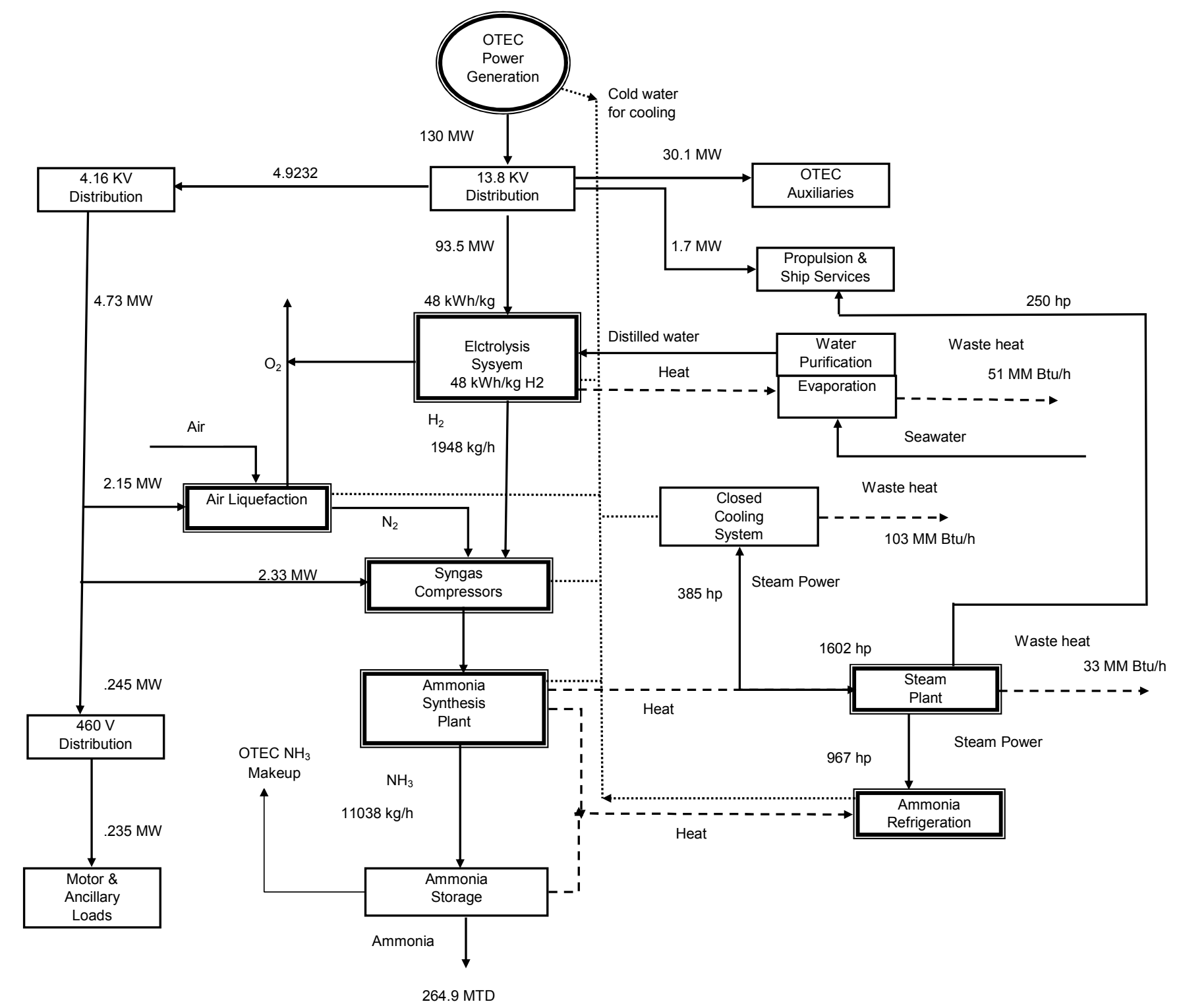

FIGURE 4.5 Energy Flow Diagram of the Ocean Thermal Plantship 
TABLE 4.3 Process Parameters of 265 MTD Plantship

\begin{tabular}{clrcc}
\hline $\begin{array}{c}\text { Flow } \\
\text { Stream }\end{array}$ & \multicolumn{1}{c}{ Description } & $\begin{array}{r}\text { Temperature } \\
\left({ }^{\circ} \mathrm{C}\right)\end{array}$ & $\begin{array}{c}\text { Pressure } \\
(\mathrm{Bar})\end{array}$ & $\begin{array}{c}\text { Mass Flow } \\
\left(10^{3} \mathrm{~kg} / \mathrm{s}\right)\end{array}$ \\
\hline & & & & \\
1 & Surface warm water supply & 26.7 & & 333.8 \\
2 & Inter-stage warm water & 25.0 & & 333.8 \\
3 & Warm water return & 23.4 & & 333.8 \\
4 & Deep ocean cold water supply & 5.5 & & 239.4 \\
5 & Inter-stage cold water & 7.7 & & 239.4 \\
6 & Cold water discharge & 9.9 & & 239.4 \\
7 & Ammonia feed to stage 2 evaporator & 14.9 & 8.94 & 2.55 \\
8 & Two-phase flow from stage 2 evaporator & 21.2 & 8.88 & 2.55 \\
9 & Liquid return from stage 2 evaporator & 21.2 & 8.88 & 0.77 \\
10 & Vapor to stage 2 turbine/generator & 21.2 & 8.88 & 1.78 \\
11 & Ammonia feed to stage 1 evaporator & 13.9 & 9.42 & 2.52 \\
12 & Two-phase flow from stage 1 evaporator & 22.8 & 9.35 & 2.52 \\
13 & Liquid return from stage 1 evaporator & 22.8 & 9.35 & 0.76 \\
14 & Vapor to stage 1 turbine/generator & 22.8 & 9.35 & 1.76 \\
15 & Vapor from stage 2 turbine/generator & 12.3 & 6.67 & 1.78 \\
16 & Stage 2 condensate & 12.3 & 6.65 & 1.78 \\
17 & Liquid return to stage 2 receiver tank & 12.3 & 8.88 & 1.78 \\
18 & Vapor from stage 1 turbine/generator & 10.1 & 6.18 & 1.76 \\
19 & Stage 1 condensate & 10.1 & 6.17 & 1.76 \\
20 & Liquid return to stage 1 receiver tank & 10.1 & 9.35 & 1.76 \\
\hline
\end{tabular}

TABLE 4.4 Energy Balance of 265 MTD Plantship

\begin{tabular}{clr}
\hline $\begin{array}{l}\text { Energy } \\
\text { Stream }\end{array}$ & \multicolumn{1}{c}{ Description } & $\begin{array}{r}\text { Power } \\
\text { (MW) }\end{array}$ \\
\hline & & \\
51 & Gross power & 130.2 \\
52 & Net power to electrolyzer & 93.5 \\
53 & Air liquefaction and SynGas compressors & 4.9 \\
& and auxiliary power & \\
54 & Warm water pumping & 13.1 \\
55 & Cold water pumping & 14.7 \\
56 & Ammonia pumps & 2.3 \\
57 & Platform propulsion & 1.7 \\
\hline
\end{tabular}




\subsubsection{Compact Brazed-Aluminum Heat Exchangers}

The original ocean thermal plantship design incorporated folded-tube heat exchangers. They were less expensive to build; however, they occupy significant space on the plantship and require higher seawater flow rates. Argonne National Laboratory, jointly with industrial partners, developed compact, high-performance brazed plate-fin heat exchangers based on commercial manufacturing processes. The thermal performances of prototypes of both heat exchanger designs were quantified at the Argonne's heat exchanger test facility (Yung et al. 1981; Panchal et al. 1981) (see test sections in Figures 4.6 and 4.7).

The overall dimensions of the folded tube heat-exchanger test section were $6.1 \times 1.2 \times 7.5 \mathrm{~m}$. For comparable heat duty, the overall dimensions of the brazed-aluminum heat-exchanger section were $0.6 \times 0.4 \times 3.2 \mathrm{~m}$. This comparison illustrates the compactness of the aluminum plate-fin heat exchanger.

An elemental-sectional view of the brazed-aluminum heat exchanger is shown in Figure 4.7. Water passages are extruded channels, and a finned surface is used for boiling and condensing the working fluid ammonia. A brazing process is used to assemble the modular heat exchanger. The brazing process has significantly advanced since the development of this heat exchanger in early 1980s. Originally, molten salt was used for brazing these heat exchangers; in the late 1980s and 1990s, vacuum brazing was developed; now, inert-gas brazing is used by leading manufacturers. The development of the inert-gas brazing process and new reliable aluminum alloys have reduced the cost of compact heat exchangers and increased their service life. In a joint long-term corrosion and biofouling research program, extruded water passages have been qualified for service life of greater than 15 years for ocean thermal plants (Panchal et al. 1990). However, further corrosion-protection developments are required for brazed joints exposed to seawater at the inlet and outlet of heat exchangers.

The brazed-aluminum heat exchangers can be commercially fabricated in sizes of up to $1.5-\mathrm{m}$ in cross section and $8.5 \mathrm{~m}$ in length, which is limited by the availability of brazing furnaces and the length of multi-channel extrusions. Individual brazed units are assembled into sub-modules at manufacturing sites, and the full-size heat exchangers (Stevens at al. 1984) can be assembled on site. These heat exchangers can be designed and fabricated for cross-flow (seawater and working fluid flow in cross flow) configuration or parallel-flow (seawater and working fluid flow in parallel flow) configuration, as was the test unit at Argonne. Performance prediction methods have been developed and validated with Argonne test data for both flow configurations (Panchal 1984); therefore, these heat exchangers can be designed and scaled-up to full-size heat exchangers with a high-level of design confidence. 


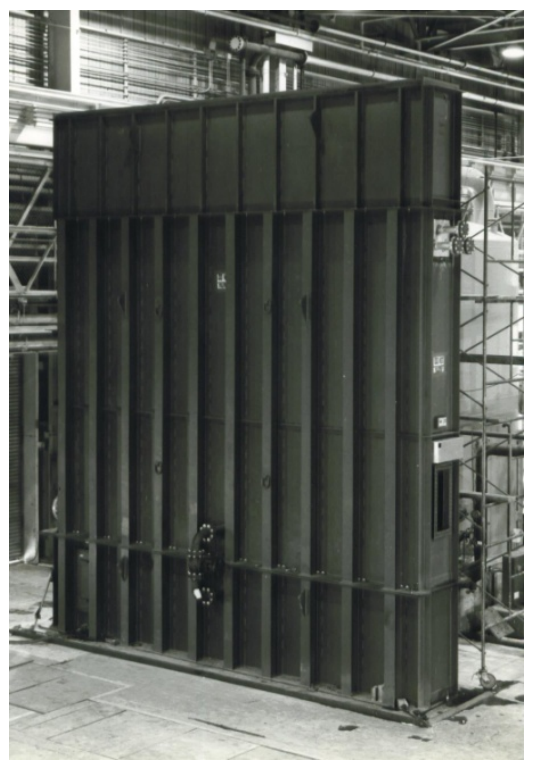

FIGURE 4.6 Test Unit of JHU/APL Folded-Tube Heat Exchanger (Source: Yung et al. 1981)
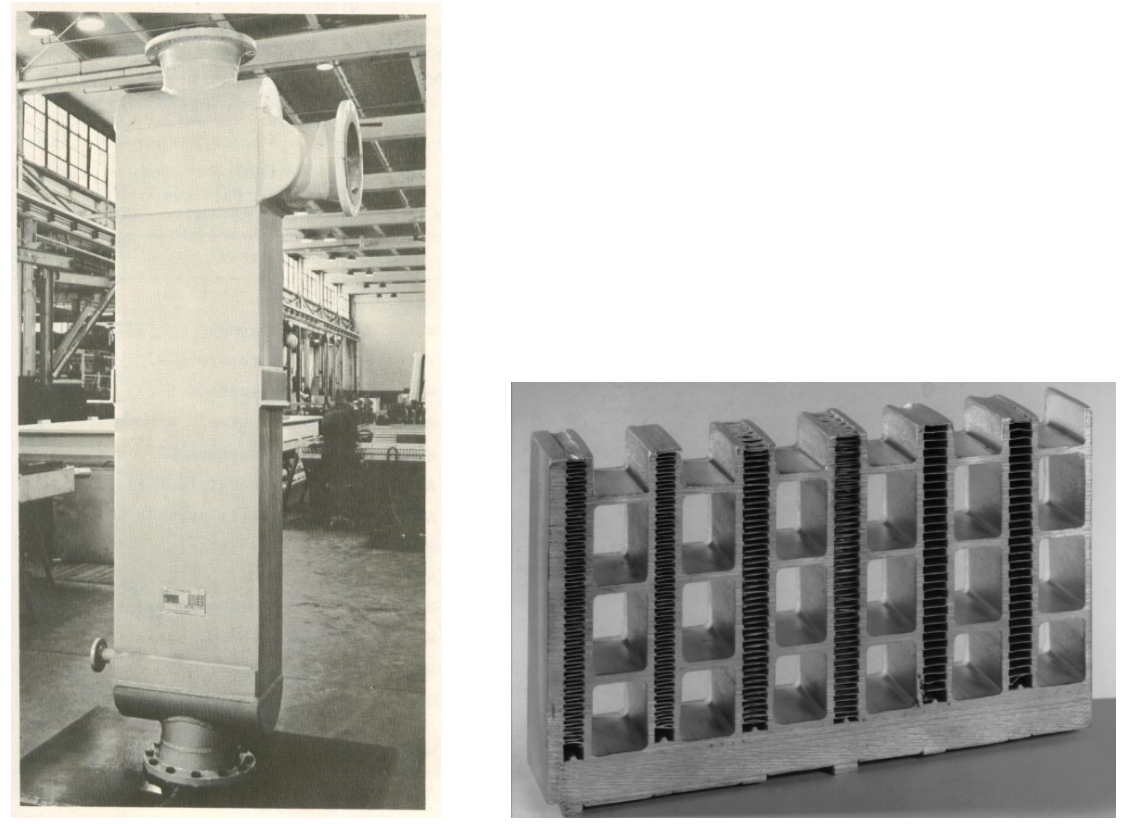

FIGURE 4.7 Test Unit and Elemental Section of BrazedAluminum Plate-Fin Heat Exchanger (Source: Panchal et al. 1981) 


\subsubsection{Plantship Integration}

In this plantship design, a vertical flow configuration was used to accommodate the compact heat exchangers in the place used for the JHU/APL folded-tube heat exchangers. Figure 4.8 shows an overlay of the assembly of brazed-aluminum heat exchangers in the original platform configuration of the JHU/APL plantship. There are 30 sub-modules in each of two sections of the plantship, as shown by the schematic layout in Figure 4.8.

The original width of the heat exchanger space was $33 \mathrm{~m}$, which is increased by $7 \mathrm{~m}$ to $40 \mathrm{~m}$. Ammonia turbine/generators and seawater pumps have smaller footprints; therefore, the platform size would be impacted only minimally with higher (130 MWe gross) generating power of the plantship, as compared to 52-MWe gross power generation in the original pilot plantship design. With the larger capacity of the ammonia turbine/generators, the number of units could be maintained at four, as in the original design, or 10 commercially available turbine/generators of $15-\mathrm{MWe}$ gross capacity can be installed without impacting the platform size significantly.

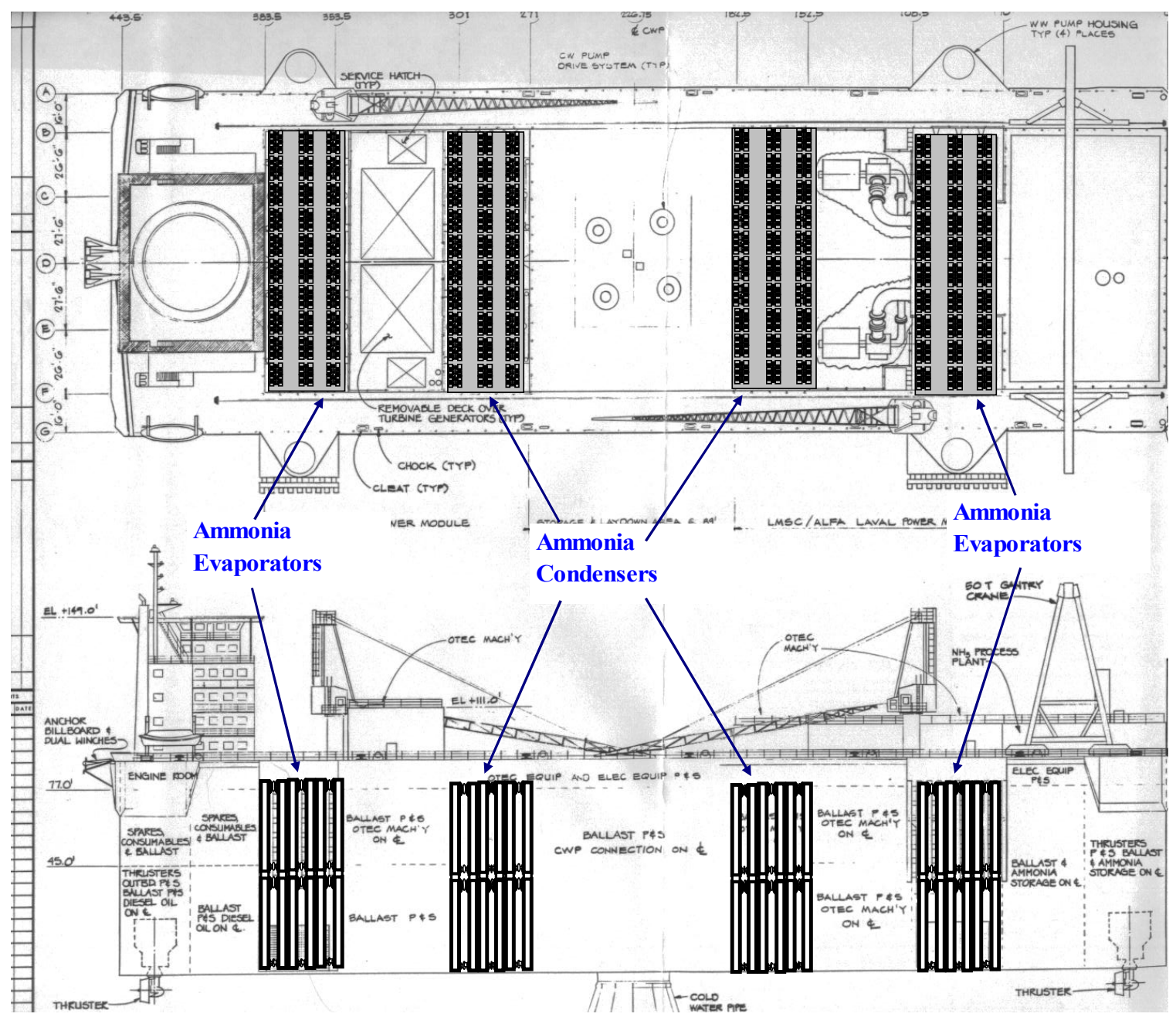

FIGURE 4.8 Plantship Layout Showing Overlay of Compact Aluminum Heat Exchangers in the JHU/APL Platform (Source: JHU/APL Report, George and Richards 1980) 
The ammonia synthesis plant had a footprint of $21 \times 33 \mathrm{~m}(70 \times 108 \mathrm{ft})$, as shown in Figure 3.4. This footprint is increased to $40 \times 40 \mathrm{~m}(130 \times 130 \mathrm{ft})$ for a larger ammonia synthesis plant. The cold-water pipe would be made of FRP, which simplifies the pipe-platform interfacing junction. However, the original design and costs are assumed in this design because significant engineering work would be required for a new design.

The plantship integration considered in this design study is at a conceptual level for a scoping-level estimate of cost. A detailed design would be required for further engineering of heat exchanger supports, ammonia turbine/generators, and seawater pumps. In a study performed after the JHU/APL design was completed, seaworthiness tests of the platform indicated modifications would be needed. These modifications applied to the outside structure only, and they would not impact the installation of the new power system of this design study.

\subsection{SOLID-STATE AMMONIA SYNTHESIS PROCESS}

A process flow diagram of the ammonia synthesis process, as applied to ocean thermal plantships, is shown in Figure 4.9. The ammonia synthesis reaction is exothermic with the heat of reaction of $11 \mathrm{~kJ} / \mathrm{mol}$ of ammonia:

$$
3 \mathrm{H}_{2}+\mathrm{N}_{2} \leftrightarrow 2 \mathrm{NH}_{3}+22 \mathrm{~kJ}
$$

The chemical equilibrium is favored to the product side by high pressure and lower temperatures. However, to maintain a high rate of reaction, a catalyst is used at high temperatures. The Haber-Bosch ammonia synthesis process consists of pressurizing the feed to 90 bar or higher and preheating to a reaction temperature of $400-500^{\circ} \mathrm{C}$.

The high-pressure steam generated in the waste-heat recovery boiler is used to run the refrigeration compressor. The refrigeration is required for recovering and storing the ammonia product at $-33^{\circ} \mathrm{C}$ and at atmospheric pressure. The nitrogen required for the ammonia synthesis is produced by using a commercial process of cryogenic air separation. Emerging non-cryogenic air-separation technologies of pressure swing adsorption (PSA) and membrane separations would reduce the energy consumption of nitrogen production. Hydrogen is produced from different sources. In the United States, it is primarily produced from natural gas, while petroleum products (naphtha, heavy gas oil, petroleum residuum) are used in other countries. Coal is also used to produce hydrogen in some countries. Energy consumption varies, depending on the source of hydrogen. A primary benchmark for energy consumption is based on natural gas, where $33 \mathrm{MBtu}$ $(9,600 \mathrm{kWh})$ equivalent of natural gas/metric ton of ammonia is required (Energetics 2000$)$. This consumption includes natural gas as feedstock, as well as an energy source. The energy consumption and, therefore, the carbon emission would be much higher for heavy gas oil, petroleum residuum, and coal as feedstock.

NHThree ${ }^{\mathrm{TM}}$, Inc., has developed an innovative solid-state ammonia synthesis process with significantly improved energy efficiency. In this process, a solid-state electrochemical process is used to synthesize ammonia by using steam and nitrogen as feedstock, eliminating a 
step to produce hydrogen from water. Figure 4.10 shows a simplified process flow diagram of the process. The electrochemical process is similar to that in a solid-oxide fuel cell (SOFC).

The electrochemical reaction path is as follows:

$$
6 \mathrm{H}_{2} \mathrm{O}+2 \mathrm{~N}_{2} \rightarrow 3 \mathrm{O}_{2}+4 \mathrm{NH}_{3}
$$

1. Water (steam) decomposes at the anode;

2. Hydrogen atoms are adsorbed in the membrane cell and stripped of electrons;

3. Hydrogen conducts (as the proton) through the proton-conducting ceramic electrolyte, emerges at the cathode, regains an electron, and reacts with adsorbed dissociated nitrogen atoms to form ammonia;

4. Ammonia is carried away by excess nitrogen for recovery and storage, similar to the conventional process; and

5. Conversion is not complete, and unreacted steam and nitrogen are recycled.

The major advantages of this process are as follows:

- Energy consumption is significantly reduced;

- The estimated energy consumption is $7,000 \mathrm{kWh} /$ ton ammonia, which is $27 \%$ lower than the energy consumption of the natural-gas-based Haber-Bosch process;

- The energy-intensive process of hydrogen production is eliminated;

- High-pressure compressors, which are required in the Haber-Bosch process, are not required;

- The solid-state modules would have a smaller footprint in comparison to the conventional Haber-Bosch process, which would reduce the platform size; and

- The modular design is ideally suited for ocean thermal plantships.

This solid-state ammonia synthesis is in the development stage by NHThree ${ }^{\mathrm{TM}}$, Inc., and it was included in the technical and economic analyses to evaluate its potential application for the ocean thermal plantships. 


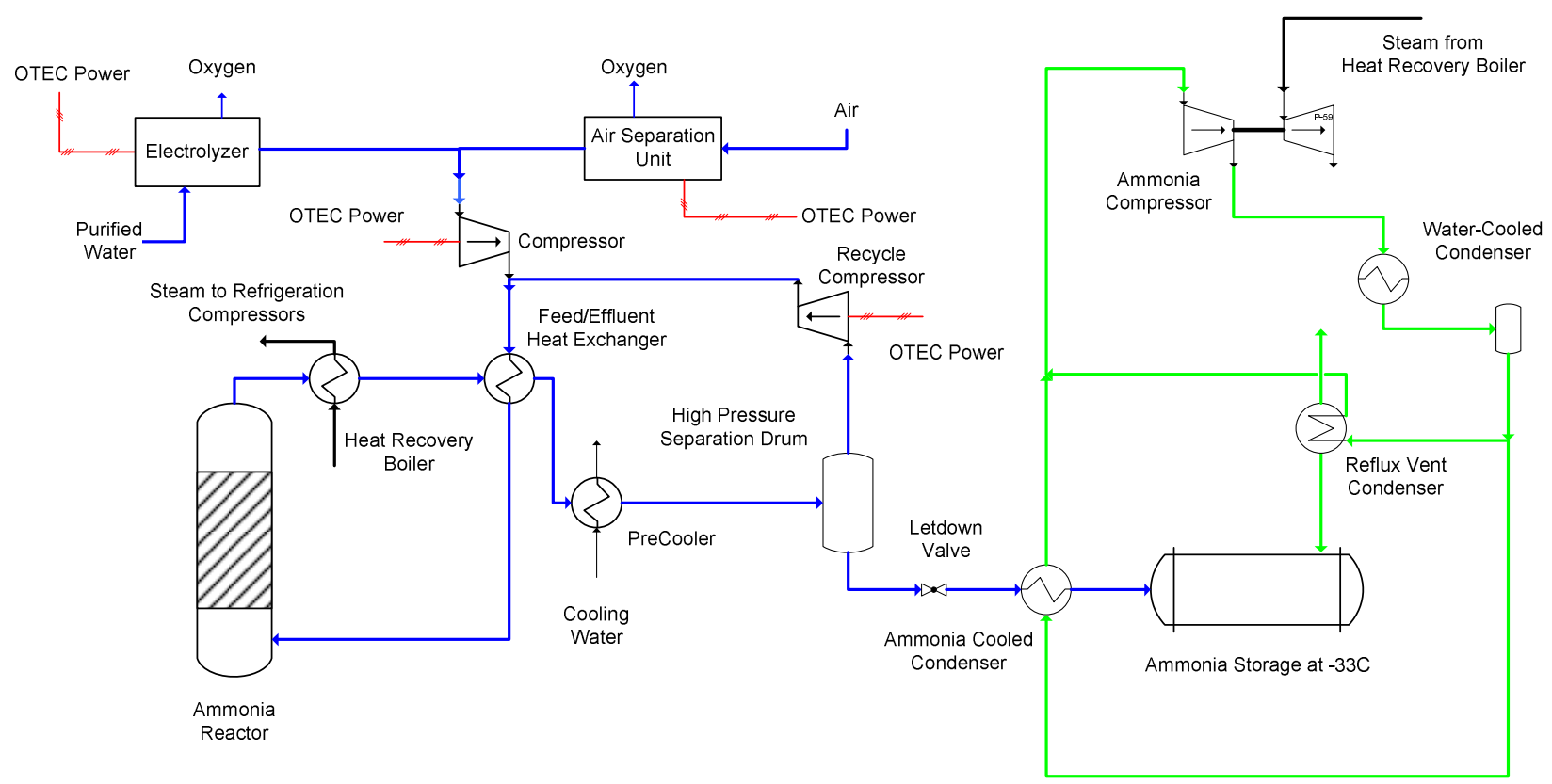

FIGURE 4.9 Simplified Process Flow Diagram of the Haber-Bosch Ammonia Synthesis Process

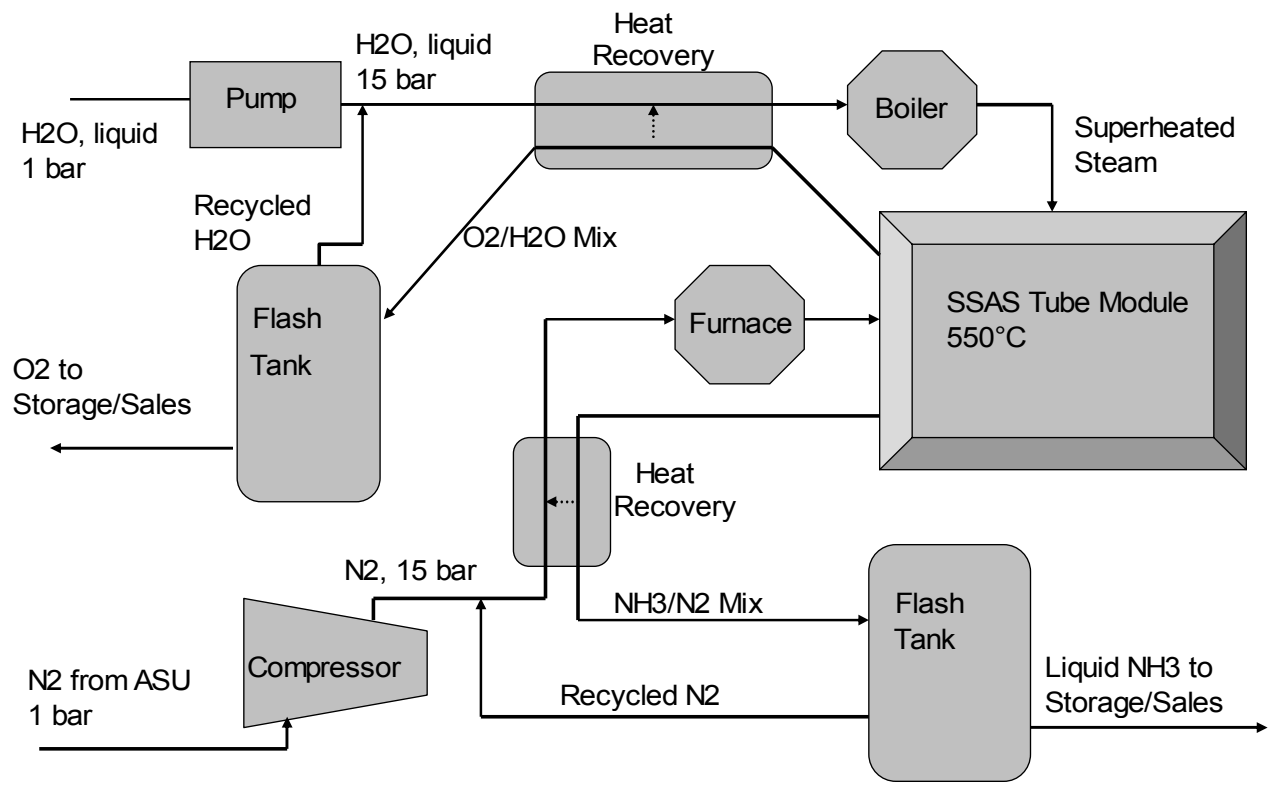

FIGURE 4.10 Process Flow Diagram of the NHThree ${ }^{\mathrm{TM}}$ Solid-State Ammonia Synthesis Process 


\subsection{HYBRID-CYCLE PLANTSHIP}

The original JHU/APL plantship was not designed for the production of desalinated water. Therefore, to evaluate the economics of co-production of desalinated water with respect to the costs of ammonia, a hybrid-cycle plantship was analyzed by incorporating a water-producing concept into the design. There are two hybrid-cycle concepts for water production. An integrated hybrid-cycle is more efficient with lower installed costs (Panchal and Bell 1987), as described in Section 4.1. The parallel-flow hybrid-cycle uses the conventional multi-stage flashing (MSF) technology (Rabas, Panchal, and Genens 1990).

The process flow diagram and the basic configuration of the parallel-flow hybrid cycle are shown in Figures 4.11 and 4.12, respectively. A three-stage flash evaporation system is an optimum configuration for the temperature gradient of the ocean thermal sources. The warm water flows into the first stage of the flash evaporator and produces low-pressure steam in the condenser, which is cooled by deep-ocean cold water. Conventionally, tube bundles are used for condensing the low-pressure stem. In a revised design, brazed-aluminum heat exchangers are proposed for improved production efficiency and reduced energy consumption (by reducing the amount of steam to be handled by the vacuum system). The warm water from the $1^{\text {st }}$ stage flows to the $2^{\text {nd }}$ stage evaporator, followed by the $3^{\text {rd }}$ stage evaporator. Each stage is operating at different operating pressures, depending on the flash-down temperature. The non-condensable gases released during the flashing of the seawater are discharged to the atmosphere by using inter-stage cooled vacuum pumps.

Although the hybrid-cycle is not necessarily an optimum design, it was considered in this analysis to keep the cost estimates consistent with the original design of the JHU/APL plantship, and the hybrid cycle cost estimates are available for the MSF technology. The major design parameters for $114 \mathrm{mlpd}$ are presented in Table 4.5. This is about one-half the water production capacity of the integrated hybrid cycle. A separate platform would be used for the waterproducing plant. The ocean thermal plantship would provide the electric power to operate seawater pumps and the vacuum system. The hybrid cycle requires parallel seawater flows, so warm- and cold-water flow rates are increased by $27 \%$ and $33 \%$, respectively. This results in increased pumping power, thereby reducing net power to $82 \mathrm{MWe}$ and ammonia production to 239 MTD. 
TABLE 4.5 Process Parameters of the Ocean-Thermal Plantship

\begin{tabular}{lcc}
\hline \multicolumn{1}{c}{ System Parameters } & $\begin{array}{c}\text { Ammonia } \\
\text { Production Only }\end{array}$ & $\begin{array}{c}\text { Co-Production } \\
\text { of Fresh Water }\end{array}$ \\
\hline Warm water temperature $\left({ }^{\circ} \mathrm{C}\right)$ & & \\
Cold water temperature $\left({ }^{\circ} \mathrm{C}\right)$ & 26.7 & \\
Warm-water flow rate $(\mathrm{kg} / \mathrm{s})$ & 5.6 & 413,850 \\
Cold-water flow rate $(\mathrm{kg} / \mathrm{s})$ & 325,970 & 364,140 \\
Gross electric generation $(\mathrm{MWe})$ & 275,130 & 130.0 \\
Net power to ammonia $\mathrm{plant}(\mathrm{MWe})$ & 130.0 & 84.3 \\
Hydrogen production $(\mathrm{kg} / \mathrm{h})$ & 93.5 & 1,756 \\
Ammonia production $(\mathrm{metric}$ tons/day) & 1,948 & 239.0 \\
Fresh water production $\left(10^{6} \mathrm{~L} /\right.$ day $)$ & 265 & 114.0 \\
\hline
\end{tabular}

Vacuum Pumps for Discharging Noncondensable Gases

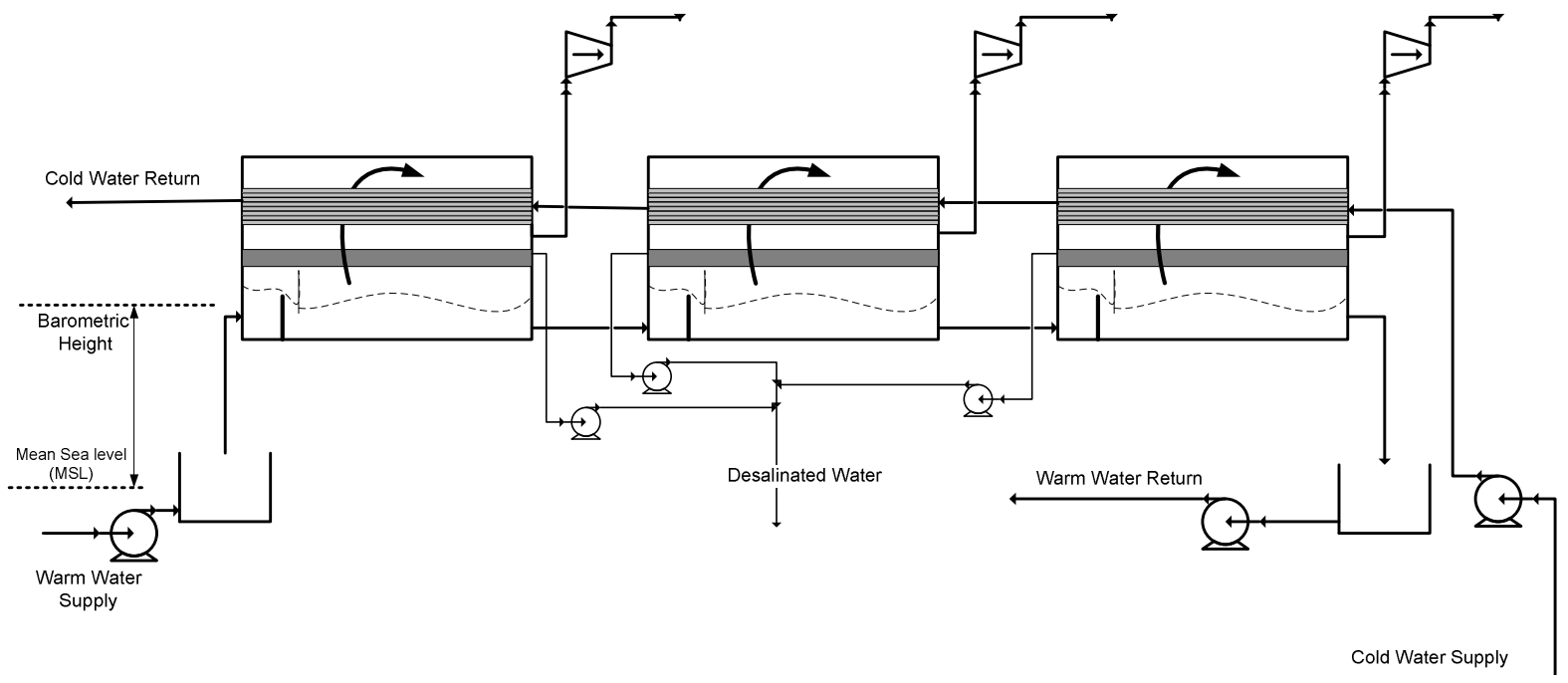

FIGURE 4.11 Flow Schematic of the Add-on-Hybrid Cycle for Production of Desalinated Water

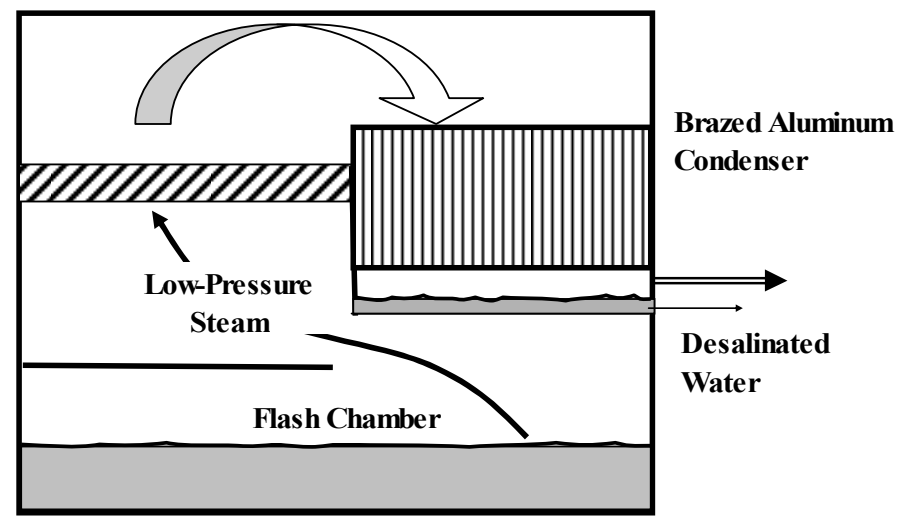

FIGURE 4.12 Schematic Layout of the Hybrid Cycle for Production of Desalinated Water 


\subsection{SATELLITE PLANTSHIP SYSTEM}

The concept of a Satellite Ocean Thermal Plantship consists of a constellation of individual ocean thermal plants providing power to a centralized commercial-scale $(2,000-$ 3,000 MTD) ammonia synthesis plant. A summary is provided in this report on the basis of a scoping-level economic analysis performed to evaluate the technical and economic merits of this concept.

A single ocean thermal plant, which can be built with the existing manufacturing capabilities and deployment of large equipment, would produce about 260 MTD of ammonia. Manufacturing capacities of commercial ammonia plants have increased to 2,000+ MTD. To match this production of commercial-scale ammonia plants, a concept is proposed to combine multiple, individual ocean thermal plants of 40-100-MWe generating capacities, which would feed the power to a single ammonia plant that has a capacity of 2,000-3,000 MTD. Depending on the market for desalinated water, some of the individual plants can be designed as integrated hybrid-cycle plants to co-produce power and desalinated water.

The technical and economic advantages of a Satellite Plantship concept are:

- A single, large-scale ammonia synthesis plant reduces the capital, as well as operating costs;

- Multiple ocean thermal plants of similar capacities reduce the deployment costs significantly;

- The logistics of transporting ammonia and desalinated water to the market place are significantly improved;

- By installing the ammonia plant on a separate platform, the design of individual plants is simplified; and

- The centralized system of operation and maintenance of the Satellite Plantships becomes cost-effective because the need for personnel and material supplies is lower.

This concept of the Satellite Plantships is based on how off-shore petroleum reserves are produced, processed, collected to a centralized location, and shipped to the market place. The Satellite Plantships is a key development for harnessing the ocean thermal resource fully, and it should be pursued with a high priority. 


\section{ECONOMIC ANALYSIS}

The purpose of the economic analysis is to establish the benchmark cost estimates of ocean thermal plantships and to evaluate the impacts of different technology scenarios on the cost of hydrogen delivered as ammonia. The basic approach of deriving cost estimates for ocean thermal plantships from previous design studies is described in Section 3.5, and the basis of estimating the total installed costs (TICs) is as follows:

1. Platform and subsystems:

- Cost estimates taken from the JHU/APL pilot plantship design

2. Heat exchangers:

- Cost algorithm developed on the basis of cost guidelines provided by the heat exchanger manufacturer

3. Rotating equipment (turbine/generator, seawater pumps):

- Scaled from budgetary quotes in the past design studies

4. Electrolyzer:

- NorskHydro electrolyzer cost quotes from the recent literature.

5. Ammonia synthesis plant:

- Commercial plant: Based on the reported cost estimates for a natural-gasbased ammonia plant and an assumption that the cost of a hydrogen-based plant is one-third the cost of a natural-gas-based plant

- Solid-state ammonia synthesis plant: Scoping-level cost estimates from NHThree ${ }^{\mathrm{TM}}$, Inc.

6. Water desalination plant:

- Desalination plant: Cost algorithms developed on the basis of literature estimates for a thermal seawater desalination plant

- Integrated hybrid cycle plant: Based on an the previous design study

7. Operation and maintenance:

- $\quad$ Based on previous design studies 
The cost estimates of the 1985 design studies were scaled to the reference year of 2005 by using the Chemical Engineering Plant Cost Index (CEPCI). Figure 5.1 shows that the CEPCI follows the producer price index (PPI) closely; the PPI is a benchmark of inflation of consumer products. By taking CEPCI in 1981 as 1.0, by 1985 the adjustment factor is 1.18 , and by 2005, this factor is 1.57 . This gives an escalation factor of 1.32 between 1985 and 2005.

Ocean thermal energy is an emerging technology that has no operating commercial or pilot plant at present. Therefore, an industrial practice of setting a $90 \%$ learning curve was followed to compare the ocean thermal technology with other renewable energy technologies being pursued for hydrogen or other energy carriers. Under this assumption, the costs of components and subsystems are reduced by $10 \%$ for every doubling of total installed capacities of ocean thermal plantships. For a third generation of ocean thermal plantships, this will yield a factor of 0.729 . This factor was applied to

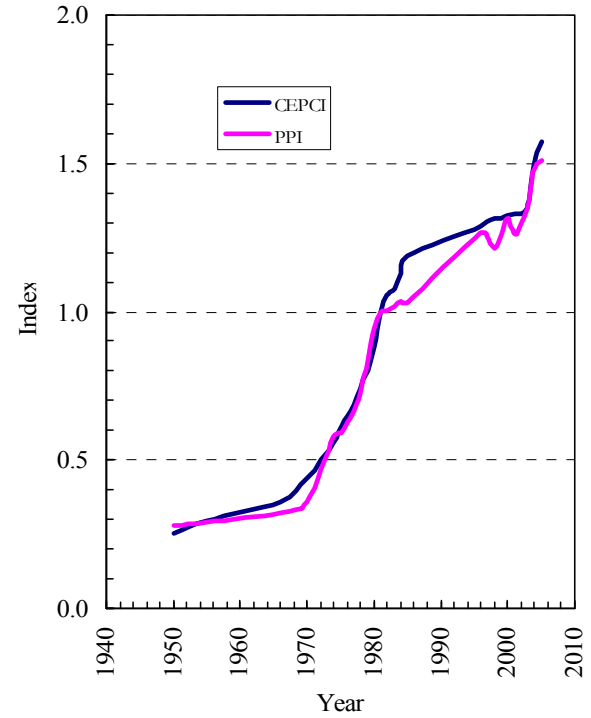

FIGURE 5.1 Chemical Engineering Plant Cost Index (CEPCI) and Producer Price Index (PPI); Indexed to Reference Year 1981 components and subsystems that are unique to the ocean thermal technology. A conservative factor of 0.85 was used for components, such as seawater pumps and ammonia turbine/generators, which are commercially manufactured, although further developments in the materials of construction could reduce their costs further and improve performance. A factor of 0.5 was used for management and design costs; the contingency was reduced from $10 \%$ for the $1^{\text {st }}$ generation to $5 \%$ for the $3^{\text {rd }}$ generation of plantships.

\subsection{WBS AND COST ESTIMATES}

The total installed costs (TIC) were estimated for the following design cases:

1. Plantship with Haber-Bosch ammonia synthesis process,

2. Plantship with a new solid-state ammonia synthesis process,

3. Plantship with the solid-state ammonia synthesis process and co-production of desalinated water,

4. Satellite plantships for commercial-scale ammonia production, and

5. Land-based integrated hybrid-cycle plantships for co-production of compressed hydrogen or ammonia and desalinated water. 
The first three cases progressively show increasing economic viability of the at-sea floating ocean thermal plantships. The fourth case shows the economics of commercial-scale plantships. The fifth case uniquely shows the economics of small land-based plantships for promising sites in the tropical regions, specifically the island states.

\subsubsection{Plantships for Ammonia Production}

The WBS and TIC for the redesigned JHU/APL plantship, representing the $1^{\text {st }}$ generation of plantships, are shown in Table 5.1. The estimated TIC of the $1^{\text {st }}$ generation plantship is \$557.1 million. The cost breakdown shows that the power system, platform, and seawater systems contribute the major costs, followed by electrolyzers and the ammonia synthesis plant.

With the maturity of the technology, the TIC of $3^{\text {rd }}$ generation plantships would be significantly reduced, as shown in Table 5.1. The TIC of $\$ 420.1$ million represents $\$ 4,494 / \mathrm{kWe}$ of power generation, or $\$ 1.58$ million per MTD of ammonia production. The commercial Haber-Bosch process was used in this design case. For comparison, the TIC of the natural-gasbased ammonia plant installed in Trinidad was \$268 million (year 2000 costs) for a 1,850-MTD plant. This is equivalent to $\$ 0.15$ million per MTD, which is about one-tenth the cost of ocean thermal plantships. The cost of natural gas, however, is the primary factor contributing to the high cost of ammonia production. This indicates that the contribution of the ammonia synthesis plant toward the TIC of ocean thermal plantships is relatively small. Therefore, an energyefficient ammonia synthesis process, even if it may have higher TIC, is required for ocean thermal plantships to reduce the production cost of ammonia.

The cost estimate presented in Table 5.1 is based on the previous design and recent cost data of the major components of the power system. To evaluate the impacts of cost uncertainties, a Monte Carlo technique was applied to the cost breakdown. Each of the 31 elements of the WBS in Table 5.1 was assigned upper- and lower-level cost bounds, and the Monte Carlo technique was performed by using a triangular distribution of costs. Figure 5.2 shows the probability distribution of the resulting TIC calculations. The median TIC of $\$ 434.8$ million is about $4 \%$ greater than the likely TIC of $\$ 418.5$ million. This is because we used skewed cost uncertainties - the higher upper bounds were given to the platform and seawater systems. The resulting multiplier of 1.04 was applied to the capital cost in the $H 2 \mathrm{~A}$ analysis. According to the Monet Carlo analysis, the best- and worst-case scenarios would result in a TIC of \$399 million and $\$ 473.3$ million, respectively. 


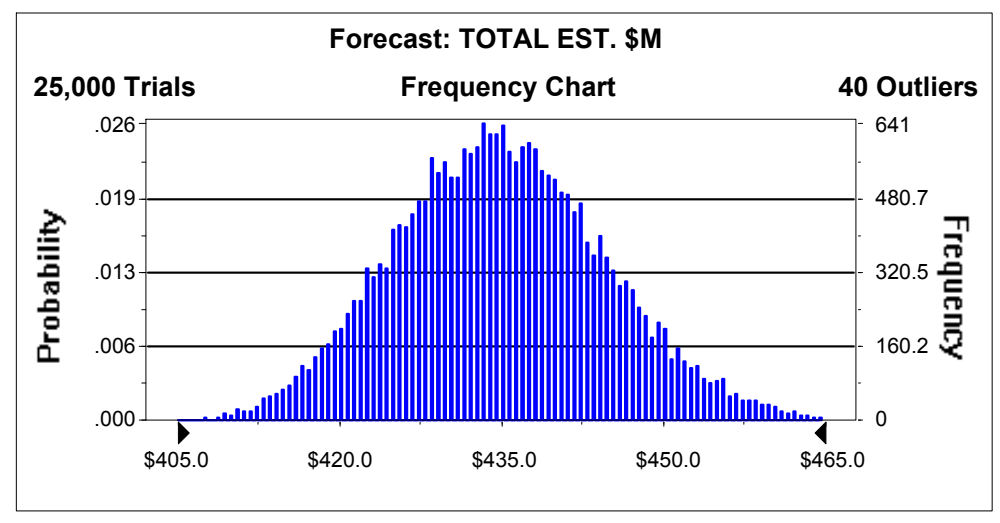

FIGURE 5.2 Probability Distribution of TIC Results from the Monte Carlo Analysis

TABLE 5.1 Total Installed Costs (TIC) of the $1^{\text {st }}$ and $3^{\text {rd }}$ Generations of Ocean Thermal Plantships

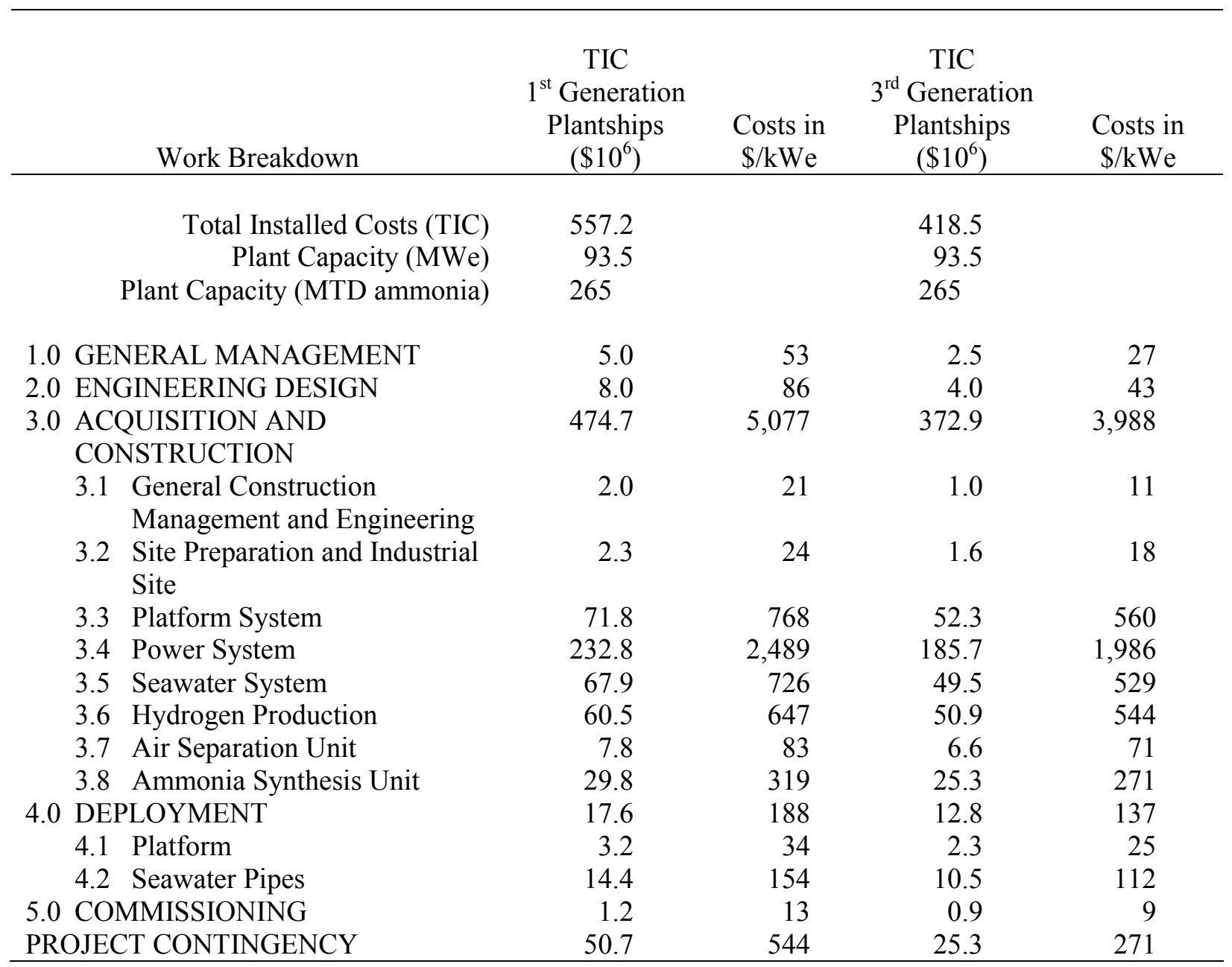




\subsubsection{Plantships with Solid-State Ammonia Synthesis Process}

The estimated energy consumption of the solid-state synthesis process is $7,000 \mathrm{kWh} / \mathrm{MT}$ of ammonia production. With this energy consumption, the plantship would produce 329 MTD from 95.9 MW, which includes power fed to the electrolyzer and power used for the SynGas compressors in the commercial Haber-Bosch ammonia synthesis process (see energy flow diagram in Figure 4.5). The cost of the solid-state process is projected by NHThree ${ }^{\mathrm{TM}}$ to be $\$ 2.0$ million per 10 MTD of ammonia production. The footprint of this process is nearly one-half the commercial Haber-Bosch process. The revised cost breakdown is shown in Table 5.2. The TIC of the plantship did not decrease significantly; however, the higher production capacity reduced the cost of the plant from $\$ 2.1$ million/MTD to $\$ 1.6$ million/MTD for $1^{\text {st }}$ generation plantships. The TIC of $3^{\text {rd }}$ generation plantships would be $\$ 1.2$ million/MTD.

TABLE 5.2 Total Installed Costs (TIC) of the Ocean-Thermal Plantships with Solid-State Ammonia Synthesis Process

\begin{tabular}{|c|c|c|c|c|c|}
\hline \multicolumn{2}{|r|}{ Work Breakdown } & $\begin{array}{c}\text { TIC } \\
1^{\text {st }} \text { Generation } \\
\text { Plantships } \\
\left(\$ 10^{6}\right)\end{array}$ & \multicolumn{2}{|r|}{$\begin{array}{c}\text { TIC } \\
3^{\text {rd }} \text { Generation } \\
\text { Plantships } \\
\left(\$ 10^{6}\right)\end{array}$} & $\begin{array}{l}\text { Costs in } \\
\$ / \mathrm{kWe}\end{array}$ \\
\hline & Total Installed Costs (TIC) & 521.7 & & 381.6 & \\
\hline & Plant Capacity (MWe) & 93.5 & & 93.5 & \\
\hline & Plant Capacity (MTD ammonia) & 329 & & 329 & \\
\hline $1.0 \mathrm{C}$ & GENERAL MANAGEMENT & 5.0 & 53 & 2.5 & 27 \\
\hline $2.0 \mathrm{E}$ & ENGINEERING DESIGN & 8.0 & 86 & 4.0 & 43 \\
\hline $3.0 \mathrm{~A}$ & $\begin{array}{l}\text { ACQUISITION AND } \\
\text { CONSTRUCTION }\end{array}$ & 474.7 & 4,732 & 337.7 & 3,612 \\
\hline & $\begin{array}{l}\text { 3.1 General Construction } \\
\text { Management and Engineering }\end{array}$ & 2.0 & 21 & 1.0 & 11 \\
\hline & $\begin{array}{l}\text { 3.2 Site Preparation and Industrial } \\
\text { Site }\end{array}$ & 2.3 & 24 & 1.6 & 18 \\
\hline & 3.3 Platform System & 71.8 & 768 & 52.3 & 560 \\
\hline & 3.4 Power System & 232.8 & 2,489 & 185.7 & 1,986 \\
\hline & 3.5 Seawater System & 67.9 & 726 & 49.5 & 529 \\
\hline & 3.6 Ammonia Synthesis Unit & 65.8 & 704 & 47.6 & 509 \\
\hline $4.0 \mathrm{I}$ & DEPLOYMENT & 17.6 & 188 & 12.8 & 137 \\
\hline & 4.1 Platform & 3.2 & 34 & 2.3 & 25 \\
\hline & 4.2 Seawater Pipes & 14.4 & 154 & 10.5 & 112 \\
\hline 5.0 & COMMISSIONING & 1.2 & 13 & 0.9 & 9 \\
\hline PRO. & DJECT CONTINGENCY & 47.4 & 507 & 23.7 & 254 \\
\hline
\end{tabular}




\subsubsection{Plantships with Co-Production of Ammonia and Water}

The TIC presented in Table 5.2 is further updated with the addition of the estimated costs of the desalination plant. As described in Section 4.4, the desalination plant is installed on an extended platform. The costs of the platform and seawater are scaled by using a scaling factor of 0.7 , which is commonly used in the industry for scaling equipment and process units. The TIC increased from \$512.7 million to \$734.2 million for the plantship with water production. Also, the ammonia production decreased from 329 MTD to 297 MTD because of the additional pumping power required for the desalination plant. The plantship produces 110 million L/day of desalinated water, which is about $50 \%$ what could be produced by using an integrated hybridcycle power system.

TABLE 5.3 Total Installed Costs (TIC) of the Ocean-Thermal Plantships with Solid-State Ammonia Synthesis Process and Co-Production of Desalinated Water

\begin{tabular}{|c|c|c|c|c|c|}
\hline & Work Breakdown & $\begin{array}{c}\text { Plantship TIC } \\
1^{\text {st }} \text { Generation } \\
\left(\$ 10^{6}\right)\end{array}$ & $\begin{array}{l}\text { Costs in } \\
\$ / \mathrm{kWe}\end{array}$ & $\begin{array}{l}\text { Plantship TIC } \\
3^{\text {rd }} \text { Generation }\end{array}$ & $\begin{array}{l}\text { Costs in } \\
\$ / \mathrm{kWe}\end{array}$ \\
\hline & Total Installed Costs (TIC) & 734.2 & & 540.8 & \\
\hline & Plant Capacity (MWe) & 93.5 & & 93.5 & \\
\hline & Plant Capacity (MTD ammonia) & 297 & & 297 & \\
\hline & Water production (mlpd) & 110 & & 110 & \\
\hline 1.0 & GENERAL MANAGEMENT & 5.0 & 53 & 2.5 & 27 \\
\hline 2.0 & ENGINEERING DESIGN & 8.0 & 86 & 4.0 & 43 \\
\hline \multirow[t]{9}{*}{3.0} & ACQUISITION AND & 627.7 & 6,713 & 481.3 & 5,148 \\
\hline & CONSTRUCTION & & & & \\
\hline & $\begin{array}{l}\text { 3.1 General Construction } \\
\text { Management and Engineering }\end{array}$ & 2.0 & 21 & 1.0 & 11 \\
\hline & $\begin{array}{l}\text { 3.2 Site Preparation and Industrial } \\
\text { Site }\end{array}$ & 2.3 & 24 & 1.6 & 18 \\
\hline & 3.3 Platform System & 71.8 & 768 & 52.3 & 560 \\
\hline & 3.4 Power System & 232.8 & 2,489 & 185.7 & 1,986 \\
\hline & 3.5 Seawater System & 67.9 & 726 & 49.5 & 529 \\
\hline & 3.6 Ammonia Synthesis Unit & 68.3 & 730 & 58.0 & 621 \\
\hline & 3.7 Desalination Water Unit & 182.7 & 1,954 & 133.2 & 1,425 \\
\hline \multirow[t]{3}{*}{4.0} & DEPLOYMENT & 25.7 & 275 & 18.7 & 200 \\
\hline & 4.1 Platform & 4.0 & 43 & 2.9 & 31 \\
\hline & 4.2 Seawater Pipes & 21.6 & 232 & 15.8 & 169 \\
\hline 5.0 & COMMISSIONING & 1.2 & 13 & 0.9 & 9 \\
\hline \multicolumn{2}{|c|}{ PROJECT CONTINGENCY } & 66.6 & 713 & 33.3 & 356 \\
\hline
\end{tabular}




\subsubsection{Land-Based Plantships for Co-Production of Ammonia and Water}

The TIC of the land-based integrated hybrid-cycle plantship was based on the Argonne design study (Panchal and Bell 1987) for a favorable site on the island of Hawaii. This design case is representative of a large number of potential tropical sites for land-based ocean thermal plantships. The original design did not include hydrogen or ammonia production, which was added in this design case. The modular design of the solid-state ammonia synthesis process is ideally suited for small land-based ocean thermal plantships. These land-based plantships are ideally suited for the island states, where compressed hydrogen can be distributed without conversion to ammonia. Alternatively, ammonia could be used for distributed power generation or in the farm equipment as a fuel and certainly as fertilizer feedstock. Therefore, both design cases of ammonia and of hydrogen production were analyzed. In general, small-scale ocean thermal plantships have very favorable economics for the island market in the prevailing petroleum cost environment, and, therefore, they should be aggressively promoted.

Table 5.4 presents the TIC of the $1^{\text {st }}$ generation of the plant as it was designed by Panchal and Bell (1985) and the TIC of $3^{\text {rd }}$ generation plantships for three design cases. The seawater system costs are site specific and could vary as much as by a factor of two, depending on the length of cold-water required for land-based sites.

\subsubsection{Production Cost of Desalinated Water}

The current worldwide capacity of existing desalination plants is over 9.4 billion gallons per day ${ }^{4}$. At present, more than 1,200 desalting plants operate in the United States, producing over 300 million gallons of water per day (MGD) (Leiner and Associates 1997). All but a few of these domestic plants desalinate brackish water. In coastal areas, as locally available sources of fresh and brackish water are depleted, large-scale seawater desalting plants would be major sources of fresh water. The first large-scale seawater desalting plant in the United States (25 MGD) began operating, albeit sporadically, near Tampa Bay, Florida, in 2003.

The four most common commercial desalination systems are (1) Reverse Osmosis (RO) membranes, (2) multi-stage flash (MSF), (3) multi-effect desalination (MED), and (4) mechanical vapor recompression (MVP). Table 5.5 presents the energy consumption considerations for three systems. Primary energy consumption of the two thermal processes (MSF and MED) is high; therefore, these systems are generally co-located with powergenerating plants using the low-pressure steam. RO is an energy-efficient process for brackish waters; however, energy consumption increases significantly for seawater.

\footnotetext{
4 The World's Water, Table 22: Installed Desalination Capacity by Year Number of Plants and Total Capacity, available at www.worldwater.org [accessed 2007].
} 
TABLE 5.4 Total Installed Costs (TIC) of the Land-Based Ocean-Thermal Hybrid-Cycle Plantships

\begin{tabular}{|c|c|c|c|c|}
\hline \multirow[b]{2}{*}{ Work Break Down } & \multirow{2}{*}{$\begin{array}{c}1^{\text {st }} \begin{array}{c}\text { Generation } \\
\text { Plant }\end{array} \\
\begin{array}{c}\text { Power and } \\
\text { Water }\end{array} \\
\text { Production } \\
\left(\$ 10^{6}\right)\end{array}$} & \multicolumn{3}{|c|}{$3^{\text {rd }}$ Generation Plantships } \\
\hline & & $\begin{array}{l}\text { Power and } \\
\text { Water } \\
\text { Production } \\
\left(\$ 10^{6}\right) \\
\end{array}$ & $\begin{array}{c}\text { Hydrogen and } \\
\text { Water } \\
\text { Production } \\
\left(\$ 10^{6}\right)\end{array}$ & $\begin{array}{c}\text { Ammonia and } \\
\text { Water } \\
\text { Production } \\
\left(\$ 10^{6}\right)\end{array}$ \\
\hline Total Installed Costs (TIC) & 88.8 & 60.5 & 65.4 & 66.3 \\
\hline Plant Capacity (MWe) & 10.0 & 10.0 & 10.0 & 10.0 \\
\hline Plant Capacity (kg/h hydrogen) & & & 208.0 & \\
\hline Plant Capacity (MTD ammonia) & & & & 34.3 \\
\hline Water production (mlpd) & 22.7 & 22.7 & 22.7 & 22.7 \\
\hline 1.0 GENERAL MANAGEMENT & 2.6 & 1.3 & 1.3 & 1.3 \\
\hline 2.0 ENGINEERING DESIGN & 6.6 & 3.3 & 3.3 & 3.3 \\
\hline $\begin{array}{l}3.0 \text { ACQUISITION AND } \\
\text { CONSTRUCTION }\end{array}$ & 69.9 & 49.1 & 49.1 & 49.1 \\
\hline $\begin{array}{l}\text { 3.1 General Construction } \\
\text { Management and Engineering }\end{array}$ & 2.0 & 1.0 & 1.0 & 1.0 \\
\hline $\begin{array}{l}\text { 3.2 Site Preparation and Industrial } \\
\text { Site }\end{array}$ & 4.0 & 2.8 & 2.8 & 2.8 \\
\hline 3.3 Building and Structures & 5.3 & 4.2 & 4.2 & 4.2 \\
\hline 3.4 Power System & 40.2 & 28.2 & 28.2 & 28.2 \\
\hline 3.5 Seawater System & 18.4 & 12.9 & 12.9 & 12.9 \\
\hline 3.6 Ammonia Synthesis Unit & & & & 5.8 \\
\hline 3.7 Hydrogen Production Unit & & & 4.9 & \\
\hline 4.0 COMMISSIONING & 1.3 & 1.0 & 1.0 & 1.0 \\
\hline PROJECT CONTINGENCY & 8.4 & 5.8 & 5.8 & 5.8 \\
\hline
\end{tabular}

TABLE 5.5 Energy Required for Desalination and Treatment of Water (Hoffman 2005; Ophir et al. 2000; Ettouney et al. 2002)

Energy Consumption

\begin{tabular}{|c|c|c|}
\hline Desalination Process & Electric $\left(\mathrm{kWh} / \mathrm{m}^{3}\right)$ & Steam $\left(\mathrm{kWh} / \mathrm{m}^{3}\right)$ \\
\hline Reverse Osmosis (RO) & $\begin{array}{l}0.7-1.2 \text { (brackish water) } \\
5 \text { (seawater) }\end{array}$ & NA \\
\hline Multi-stage flashing (MSF) & 5 & 76.4 \\
\hline \multicolumn{3}{|l|}{ Multi-effect desalination (MED) } \\
\hline - Thermal & 3 & 76.4 \\
\hline $\begin{array}{l}\text { - Mechanical vapor recompression } \\
\text { (MVR) }\end{array}$ & 7 & NA \\
\hline Water treatment & $652 \mathrm{kWh} /$ acre-foot & $\left.0.53 \mathrm{kWh} / \mathrm{m}^{3}\right)$ \\
\hline
\end{tabular}


Table 5.6 presents a cost breakdown of a design study for a $10-\mathrm{mlpd}$ desalination plant ${ }^{5}$. This case study is based on quoted total installed cost and performance parameters. An electric rate of $\$ 0.075 / \mathrm{kWh}$ was assumed to estimate the cost of energy. Thermal processes, in general, use steam from the power plant; therefore, the energy cost is based on power lost due to extracting steam from the intermediate-pressure stage of the steam turbine, which is the heat source for desalination.

To derive the cost of water to incorporate into the $\boldsymbol{H} \boldsymbol{2} \boldsymbol{A}$ analysis, the seawater RO (SWRO) process is used as the reference, and $1985 \$$ costs were scaled to $2005 \$$ by using the CEPCI of 1.32 . The resulting $\$ 1.32 / \mathrm{m}^{3}$ ( $\$ 5 /$ thousand gallons) of desalinated water was used in the $\boldsymbol{H} \mathbf{2} \boldsymbol{A}$ analysis.

\section{TABLE 5.6 Cost Breakdown of Desalinated Water Production}

\begin{tabular}{|c|c|c|c|c|}
\hline \multirow[b]{2}{*}{ Desalination Process } & \multicolumn{3}{|c|}{1985} & \multirow{2}{*}{$\begin{array}{c}2005 \\
\text { Equivalent } \\
\text { SWRO } \\
\end{array}$} \\
\hline & MSF & MED & SWRO & \\
\hline $\begin{array}{l}\text { Total Installed Costs (TIC) (\$) } \\
\text { Annual costs }\end{array}$ & $10,834,000$ & $11,500,000$ & $10,238,000$ & $13,565,350$ \\
\hline Depreciation over 10 years $(\$)$ & $1,083,400$ & $1,150,000$ & $1,023,800$ & $1,356,535$ \\
\hline Electric power $(\mathrm{kW})$ & 1,541 & - & 2,900 & 2,900 \\
\hline Costs at $\$ 0.075 / \mathrm{kWh}(\$)$ & 915,354 & - & $1,722,600$ & $1,722,600$ \\
\hline Thermal energy as lost power $(\mathrm{kW})$ & 4,700 & 4,700 & - & - \\
\hline Costs at $\$ 0.075 / \mathrm{kWh}(\$)$ & $2,791,800$ & $2,791,800$ & - & - \\
\hline Membrane replacement (\$) & 0 & 0 & 342,000 & 453,150 \\
\hline Cartridge filters (\$) & 0 & 0 & 52,000 & 68,900 \\
\hline Chemicals (\$) & 130,700 & 130,700 & 196,000 & 259,700 \\
\hline Maintenance and Parts (\$) & 200,000 & 200,000 & 200,000 & 265,000 \\
\hline Operating labor (\$) & 180,000 & 180,000 & 180,000 & 238,500 \\
\hline Total annual cost $(\$)$ & $5,301,254$ & $4,452,500$ & $3,716,400$ & $4,364,385$ \\
\hline Cost of water $\left(\$ / \mathrm{m}^{3}\right)$ & 1.61 & 1.35 & 1.13 & 1.32 \\
\hline$\$ / 10^{3} \mathrm{gal}$ & 6.09 & 5.11 & 4.27 & 5.01 \\
\hline
\end{tabular}

5 Water Desalination Report, available at www.waterdesalinationreport.com [accessed May 22, 1986]. 


\subsection{H2A ANALYSIS}

The TICs for different design cases were incorporated into the $\boldsymbol{H} \boldsymbol{2} \boldsymbol{A}$ program, and the resulting production cost of ammonia was calculated. Financial parameters of the $\boldsymbol{H} \boldsymbol{2} \boldsymbol{A}$ program are presented in Table 5.7. All financial parameters, except the capacity factor, are based on $\boldsymbol{H} \boldsymbol{2} \boldsymbol{A}$ guidelines. The capacity factor of ocean thermal plantships is influenced by the seasonal variation of temperature gradient and planned maintenance schedule. Plantships will be designed to take advantage of higher temperature gradients during the summer months and to compensate for the lower temperature gradient during the winter months. The annual average capacity can be maintained with the proper design of key components, such as seawater pumps to vary flow rates and ammonia turbine/generators to vary generating capacity. Because of the modular power system, the plantships will operate without total shutdown for an extended period (approximately five years). During the maintenance of individual power-system modules lasting over few weeks, the plantship's capacity will be maintained at a minimum of $86 \%$. The resulting overall annual capacity factor of $92.3 \%$ is achievable for ocean thermal plantships.

The $\boldsymbol{H} \mathbf{2 A}$ analysis does not take into consideration the tax credit for renewable energy, the carbon credit, or the federal loan guarantees for ocean energy that would qualify for lower interest rates.

The production cost of ammonia for at-sea ocean thermal plantships is presented in Table 5.8. For comparison, the hydrogen cost is presented on the basis of the stochiometric balance between ammonia and hydrogen. Two design cases are presented in Table 5.8. The design case of a single plantship consists of individual plantships deployed with self-supported operating staff and technical support. An operating crew of 31 people is estimated. Scheduled maintenance will be generally performed by contracting companies, which is a common industrial practice. However, the satellite plantships system will consist of multiple individual ocean thermal plants feeding power to a centralized floating ammonia synthesis plant. In this

TABLE 5.7 Financial Parameters of the $H 2 A$ Analysis

\begin{tabular}{lc}
\hline \multicolumn{1}{c}{ Parameter } & Value \\
\hline & \\
After-tax real internal rate of return (IRR) (\%) & 10 \\
Depreciation period (yr) & 20 \\
Depreciation type & Straight line \\
Analysis period and plant life (yr) & 40 \\
Assumed inflation rate (\%) & 1.9 \\
State income tax (\%) & 6 \\
Federal income tax (\%) & 35 \\
Effective income tax (\%) & 38.9 \\
Operating capacity factor (\%) & 92.3 \\
\% Equity financing & 100 \\
Construction period (yr) & 3 \\
Salvage value of the plant (5) & 20 \\
Decommissioning cost (\% of depreciable costs) & 10 \\
\hline
\end{tabular}


TABLE 5.8 Cost of Hydrogen: At-Sea Ocean Thermal Plantships

\begin{tabular}{|c|c|c|c|c|}
\hline \multirow[b]{2}{*}{ Parameter } & \multicolumn{3}{|c|}{ Single Plantship } & \multirow{2}{*}{$\begin{array}{c}\text { Satellite } \\
\text { Plantships } \\
\\
\text { Solid-State } \\
\text { Process }\end{array}$} \\
\hline & $\begin{array}{c}\text { Haber- } \\
\text { Bosch } \\
\text { Process }\end{array}$ & $\begin{array}{l}\text { Solid-State } \\
\text { Process }\end{array}$ & $\begin{array}{l}\text { With Water } \\
\text { Production }\end{array}$ & \\
\hline Total installed cost $\left(\$ 10^{6}\right)$ & 418.5 & 381.6 & 540.8 & $3,744.3$ \\
\hline \multicolumn{5}{|l|}{ Plant capacity } \\
\hline Ammonia (MTD) & 265 & 329 & 297 & 3,290 \\
\hline Hydrogen $(\mathrm{kg} / \mathrm{h})$ & 1,948 & 2,418 & 2,183 & 24,180 \\
\hline Water production (mlpd) & & & 114 & \\
\hline (L/kg hydrogen) & & & 2,167 & \\
\hline \multicolumn{5}{|c|}{ Hydrogen Cost Contribution $(\$ / \mathrm{kg})$} \\
\hline Capital & 4.58 & 3.60 & 5.20 & 3.30 \\
\hline Fixed O\&M & 1.46 & 1.13 & 1.62 & 0.98 \\
\hline Water production credit & & & 3.02 & \\
\hline Ammonia cost (\$/MT) & 1,066 & 835 & 670 & 755 \\
\hline Hydrogen cost $(\$ / \mathrm{kg})$ & 6.04 & 4.73 & 3.80 & 4.28 \\
\hline
\end{tabular}

case, the operating crew for each plant will be reduced to less than 10 , with a total operating crew of 150 people.

The three design cases of singular plantships we examined are as follows:

1. The design of the JHU/APL plantship is updated with compact aluminum heat exchangers and a commercial Haber-Bosch ammonia synthesis process,

2. The Haber-Bosch process is replaced with a solid-state ammonia synthesis process, and

3. Plantships have a desalinated water production plant.

The $\boldsymbol{H} \mathbf{2 A}$ analysis shows that with systematic technology developments and taking advantage of co-production of desalinated water, the production cost of hydrogen would meet the HFCIT goals of producing hydrogen at a cost of $\$ 3 /$ gge (delivered, untaxed, 2005\$, by 2015 ).

The cost of hydrogen for a land-based plant using an integrated hybrid-cycle power cycle is presented in Table 5.9. It includes two design cases: (1) a solid-state ammonia synthesis process and (2) an electrolyzer for hydrogen production. For an integrated hybrid-cycle plant, the cost would be even lower, as shown in Table 5.9, for land-based plant. However, there is no design study of a large-scale, at-sea, hybrid-cycle plantship, which could have been used as a reference design in this analysis. The $\boldsymbol{H} \boldsymbol{2} \boldsymbol{A}$ results presented in Table 5.9 show that the production cost of ammonia and compressed hydrogen would be less than $\$ 3 / \mathrm{kg}$. However, it will require a local market of desalinated water at a price competitive to the RO process. 
TABLE 5.9 Cost of Hydrogen: Land-Based Hybrid-Cycle Ocean-Thermal Plantships

\begin{tabular}{lcc}
\hline \multicolumn{1}{c}{ Parameter } & $\begin{array}{c}\text { Ammonia } \\
\text { Production }\end{array}$ & $\begin{array}{c}\text { Hydrogen } \\
\text { Production }\end{array}$ \\
\hline Total Installed cost $\left(\$ 10^{6}\right)$ & 66.3 & 65.4 \\
Plant capacity & & \\
Ammonia $(\mathrm{MTD})$ & 34.3 & \\
Hydrogen $(\mathrm{kg} / \mathrm{h})$ & 252.1 & 208.0 \\
Water production $(\mathrm{mlpd})$ & 22.7 & 22.7 \\
(L/kg hydrogen) & 3,750 & 4,547 \\
Hydrogen Cost Contribution $(\$ / \mathrm{kg})$ & & 6.31 \\
Capital & 5.29 & 2.37 \\
Fixed O\&M & 1.98 & 6.15 \\
Water production credit & 5.01 & 2.53 \\
Ammonia cost $(\$ / \mathrm{MT})$ & 399 & \\
Hydrogen cost $(\$ / \mathrm{kg})$ & & \\
\hline
\end{tabular}

The production cost of ammonia varies from a high value of $\$ 1,066 / \mathrm{MT}$ for the HaberBosch-based plantship without water production to a promising low value of \$399/MT for a solid-state, land-based hybrid-cycle plant with co-production of desalinated water at full capacity. The solid-state process, with its high energy efficiency, significantly improves the economics by increasing the ammonia production capacity with lower TICs.

In summary, the H2A analysis shows the potential of mature technology of ocean thermal plantships to meet the cost goal. Innovative engineering and fabrication techniques will be required to reduce fabrication and deployment costs. The key developments required to meet the hydrogen goal are (1) the development of an energy-efficient ammonia synthesis process; (2) the development of the integrated hybrid cycle based on low-cost, high-performance compact aluminum heat exchangers; and (3) new and improved designs for platforms and a seawater system. 


\section{WORKSHOP}

A one-day workshop was held at the L'Enfant Plaza Hotel, Washington, D.C., on September 11, 2007. There were over 50 participants, including more than 33 representatives from industry. It was one of the largest gatherings of the ocean thermal community in recent years. The primary purpose was to present to a peer-review audience the results of the analyses of this design study. Industry experts were invited to present their ongoing ocean thermal technology and business developments. Also in attendance were participants from federal agencies and congressional staff, including The Maritime Administration/DOT, DOE/EERE, the National Oceanic and Atmospheric Administration (NOAA), Naval Facilities Engineering Command, and the Select Committee on Energy Independence \& Global Warming.

Congressman Hon. Roscoe Bartlett (MD-District 6), a leading national spokesman on energy issues, presented his views of the global energy situation - he focused on the gap that would be created in the post-peak oil-production era. He pointed out that no single energy solution will fill the gap; therefore, all potential energy technologies, including ocean thermal energy, should be included in the U.S. energy portfolio.

\subsection{OBJECTIVES}

To meet the workshop objectives, the following project-specific tasks were presented to the participants:

- Examine the viability of ocean thermal plantships in the global energy environment anticipated in the next several decades,

- Review the design and economic analyses of an ocean thermal plantship, and

- Discuss the industrial perspectives of ocean thermal energy technology in the foreseeable future and conduct an open forum discussion for defining a path forward to commercialize ocean thermal plantships.

\subsection{AGENDA}

The workshop agenda was as follows:

9:00 AM Welcome and Introduction

CB Panchal, Argonne

9:10 AM Historical Perspectives

Robert Cohen, Cohen Foundation

9:20 AM Recent Developments of Ocean Thermal Energy

Peter Pandolfini, JHU/APL 
9:30 AM Global Peak Oil and Alternatives

Rep. Roscoe Bartlett, 6th District, Maryland

10:30 AM Ocean Thermal Energy and The Energy-Water Nexus

William Kumm, Arctic Energies Ltd.

10:45 AM Solid State Technology for Ammonia Synthesis

11:00 AM Project Review

Jason Ganley, Howard University

Introductory Remarks

Mark Paster, Program Manager, U.S. Department of Energy

Technical and Economic Analyses of Ocean Thermal Plantships

CB Panchal, Argonne

12:30 PM

Lunch

$1: 30 \mathrm{PM}$

Industrial Perspectives and Ongoing Ocean Thermal Developments

Chair: Peter Pandolfini

- Hans Krock, Ocean Engineering and Energy Systems (OCEES)

- Patrick Grandelli, Makai Ocean Engineering, Inc.

- Michael Panich and Robert Methot, New West Technologies, LLC

- James Anderson Jr., Sea Solar Power (SSP), Inc.

- Thomas Plocek, Offshore Infrastructure Associates, Inc.

- Mike McCloskey, FDE Solutions Corp.

2:30 PM Open Forum Discussion

Defining Ocean Thermal Goals

Moderator: CB Panchal

Achieving Ocean Thermal Goals

Moderator: Peter Pandolfini

5:00 PM Workshop Adjourned

\subsection{PROJECT REVIEW}

The project review focused on whether ocean-thermal-produced hydrogen, delivered as ammonia, is competitive with other renewable energy technologies being pursued to meet the DOE cost goal for hydrogen or an alternative energy carrier. A summary of key points discussed at the workshop is presented here.

- With the present commercial manufacturing capabilities, ocean thermal plantships of nominal production capacity of 265 MTD can be built and commercialized by 2015 .

- The industry participants, in general, did not raise any technical issues with the design approach or the benchmark estimated cost of producing ammonia and desalinated water. 
- The cost of hydrogen delivered as ammonia for third-generation ocean thermal plantships (without production of desalinated water) with a learning curve of $90 \%$ of cost reduction for doubling the capacity would be twice the DOE's current hydrogen cost goal.

- With water production, depending on the market value of desalinated water, the cost of hydrogen comes closer to the DOE cost goal.

- The following three technology advancements were identified for improving the economics of ocean thermal plantships to meet DOE's cost goal:

1. A new process of solid-state ammonia synthesis, which would be about $30 \%$ more energy efficient than the commercial process used in the present analysis (this process was developed by NHThree ${ }^{\mathrm{TM}}$, Inc. and presented at the Workshop);

2. A commercial-scale ocean thermal plantship system sized to produce 2,000-3,000 MTD with co-production of desalinated water using Argonne's integrated hybrid-cycle ocean thermal power system; and

3. Non-cryogenic pressure-swing adsorption (PSA) and membrane air separations for nitrogen production.

\subsection{OPEN FORUM DISCUSSION}

The key issues discussed in the open forum are as follows:

1. The six long-term goals related to ocean thermal energy discussed at the workshop and presented in chronological order are:

I. Global displacement of petroleum-fuel-based (diesel, fuel oil, naphtha) power generation for freeing up these fuels for transportation, chemical feedstock, and other high-valued uses;

II. At-sea production of desalinated water for regions of critical water shortages;

III. Displacement of carbon-based feed stocks and energy for the production of ammonia fertilizers;

IV. Hydrogen supply to allow economic processing of heavy crude oils and upgrading oil sands; 
V. Ammonia-fueled distributed energy to displace natural-gas-fueled power generation to free up natural gas for higher-value uses and mitigating issues associated with imported liquefied natural gas (LNG); and

VI. Use of ammonia as a hydrogen carrier for transportation.

The industry is pursuing the first goal of commercialization of ocean thermal plants for the island market (and, to some extent, the second goal). To make ocean thermal energy a viable option, long-term R\&DD should focus on delivering ammonia as the energy carrier to the U.S. continent and provide desalinated water to regions with severe shortages of fresh water.

2. There is general perception that the first commercial-scale ocean thermal plant will be deployed within five to ten years on one of the islands, where the cost of electricity has increased significantly because of great uncertainty about costs and the supply of refined petroleum liquid fuels on a global market.

3. Participants argued that production of desalinated water should be emphasized. Ocean thermal is the only energy technology that co-produces energy and water, rather than consuming water for energy production or consuming energy for producing potable water.

4. There is a niche market for small ocean-thermal plants, floating or land-based, especially with co-production of desalinated water. The DOD's Naval Facilities is interested in small ocean-thermal plants for Army and Navy bases. The cost of diesel-powered generation is high, and the volatility of supply could have an adverse impact on their operations.

There was an intense discussion on why DOE has a negative perception about ocean thermal energy conversion (OTEC). Participants could not assess the major reason(s) for this problem; however, participants collectively would like to overcome the negative perception through active industry participation. One option considered is to change the name from OTEC to Ocean Thermal Energy, which is consistent with other forms of energy we recognize (e.g., nuclear energy, geothermal energy, fossil energy, and wind energy). 


\section{CONCLUSIONS}

The primary objective of this project was to evaluate the technical and economic viability of ocean thermal plantships for the production of ammonia as the energy carrier. This objective was achieved by completing project tasks consisting of updating the JHU/APL pilot plantship design and extrapolating it to commercial plantships, evaluating a new energy-efficient ammonia synthesis process and incorporating it into the plantship system, evaluating the co-production of desalinated water on a plantship, and developing a conceptual design of satellite plantships systems for commercial-scale ammonia production. In addition, an industrial workshop was organized to present the results and develop future goals for commercialization of ocean thermal plantships by 2015 .

Ocean thermal energy has been perceived to be limited to providing power to selected tropical sites and very unlikely to be competitive with conventional fossil-energy. However, since the 1970s, the global energy, environment, and economic climate have changed drastically. This design study suggests that ocean thermal technology is a viable technology for hydrogen, delivered as ammonia; therefore, it should be pursued along with other renewable energy technologies.

Without an operating pilot plant or commercial plants, the technical and economic viability must be demonstrated with advanced concepts of an integrated system that incorporates the results from previous $R \& D$ efforts and the recent developments of design and fabrication technologies. Precisely this approach was used in this design study.

The specific conclusions and relevant facts are presented from the viewpoint of how the

ocean thermal resource can meet the future needs of energy, desalinated water, and commodity products.

Ocean Thermal Energy Technology:

- The basic design of the JHU/APL pilot plantship can be scaled to commercial plantships for at-sea production of ammonia. That was the intent of the original designers.

- Compact aluminum heat exchangers significantly improve the viability of plantships.

- The solid-state ammonia synthesis process increases the production rate by more than $25 \%$, at lower capital costs, in comparison with the commercial Haber-Bosch process.

- Co-production of desalinated water makes the ocean thermal technology viable in the near future. 
- Modular power systems employing brazed-aluminum heat exchangers reduce the technical risk.

Ammonia as the Energy Carrier:

- Ammonia transportation and storage is a well-established technology in the fertilizer industry.

- Ammonia can be cracked at elevated temperature to generate hydrogen on site.

- Ammonia fuel-cell and combustion technologies are feasible for distributed power generation.

Ammonia as Fertilizer:

- At-sea ocean thermal plantships could be a major source of ammonia production from non-carbon renewable and sustainable energy supply.

- Currently, the worldwide annual consumption of ammonia is about 140 million tons.

- At a rate of $33,000 \mathrm{ft}^{3} /$ ton of ammonia, consumption of natural gas is about 4,620 billion $\mathrm{ft}^{3} / \mathrm{yr}$. This consumption is equivalent to carbon emissions of 66 million metric tons annually. Other countries use petroleum residuum and coal, which would increase emissions even more.

- The United States imports nearly 50\% of 16 million tons of ammonia for consumption from various countries, and a major part of the ammonia is being transported via a pipeline from the Louisiana coast to the Midwest states.

- Recently, the cost of ammonia has been very volatile, ranging from a high value $>\$ 600 / \mathrm{MT}$ to a low value of $<\$ 150 / \mathrm{MT}$ FOB Tampa, Florida. The future price of ammonia is highly uncertain.

Desalinated Water:

- Three design options were evaluated for co-production of ammonia and desalinated water.

- Co-production of desalinated water significantly improved the overall economics for near-term commercialization of ocean thermal plantships. 


\section{Cost of Hydrogen:}

- The cost of hydrogen delivered as ammonia would be greater than $\$ 6 / \mathrm{kg}$ with the existing technology, and a significant reduction in total installed costs would be required to achieve the cost goal of $\$ 3 / \mathrm{kg}$.

- The cost would be significantly reduced to achieve the cost goal by two major developments: (1) an energy-efficient solid-state ammonia synthesis process and (2) an integrated hybrid-cycle power system.

- Satellite plantships will further reduce the cost of production as ammoniaproduction plants are scaled up to commercial scale. 


\section{RECOMMENDATIONS}

In this section, we present the major recommendations for making the technology of ocean thermal plantships ready by 2015 as a non-carbon renewable sustained source of energy and desalinated water.

Ocean thermal plantships with integrated hybrid cycle:

- To derive reliable cost estimates and identify technical barriers, design of a commercial-scale plantship should be performed.

- A market analysis is needed for future supply and demand of fresh water to evaluate the potential of desalinated water for the Gulf of Mexico Coastal States and southern California, as well as other global regions.

- An integrated flash evaporator and steam condenser/ammonia evaporator is a crucial component of the hybrid cycle, which requires innovative design concepts and fabrication techniques for a modular power system.

Components, subsystem, and sensor developments:

- Significant progress has been made in the development of the application of brazed-aluminum heat exchangers to the ocean thermal power system. However, there are salient design and fabrication issues associated with aluminum heat exchangers that should be resolved to reduce the technical risk of a service life of $20+$ years.

- The industry needs to invest in the design and the development of larger ammonia turbines and alternative materials for seawater pumps.

- State-of-the-art sensors should be developed to monitor components and subsystems, such as the cold-water pipe, biofouling and corrosion of heat exchangers, purity of the working fluid, and the performance of seawater pumps.

- The previous R\&D and demonstration work of the cold-water pipe should be reviewed, and new design and deployment techniques should be evaluated.

- The petroleum industry has made significant developments in designing and deploying offshore platforms. Such developments should be incorporated into the design and deployment of ocean thermal plantship platforms. In addition, innovative platform design concepts are being developed for various applications, and they should be evaluated for application to ocean thermal plantships, and the necessary development should be pursued. 
Solid-State Ammonia Synthesis Process:

- Economics of ocean thermal plantships depend on an energy-efficient ammonia synthesis process. The solid-state ammonia synthesis is an innovative process that should be developed for ocean thermal plantships.

- A prototype system should be designed for performance validation.

Logistics of transporting large quantities of ammonia and desalinated water:

- Ammonia is being transported across the world's oceans and shipped to the market place in the continental United States. However, the logistics of transporting and storing large quantities of ammonia as the hydrogen carrier should be analyzed. A report by Rise National Laboratory (Duijm et al. 2005) provides a comprehensive analysis of ammonia as a transportation fuel.

Hydrogen supply to refining and petrochemical plants in the Gulf of Mexico states:

- A specific scenario of supplying hydrogen and desalinated water to oil refineries in the Gulf of Mexico Coastal states should be analyzed. Hydrogen will be used to produce cleaner transportation fuels from heavy crude oils from Canada, Mexico, South America, and West Africa. Hydrogen consumption in a typical refinery is $100-200 \mathrm{scf} / \mathrm{barrel}$ of crude oil processed. Because of environmental regulations and processing of heavy crudes, the demand for hydrogen has been increasing by $4 \%$ per year, and it is expected rise to $5-10 \%$ per year as more refineries start processing heavy crude oils. The combined refining capacity of the Gulf of Mexico Coastal States and California refineries is more than $40 \%$ of the total U.S. refining capacity. These refineries and petrochemical plants also need significant amounts of fresh water - refineries use between 65 and 100 gal of water per barrel of crude oil processed. Desalinated water from ocean thermal plants can alleviate the local coastal water supply problem. 


\section{REFERENCES}

Avery, W.H., 1988, “A Role for Ammonia in the Hydrogen Economy,” International Journal of Hydrogen Energy 13(12):761-773.

Avery, W.H., and C. Wu, 1994, Renewable Energy from the Ocean; A Guide to OTEC, Oxford University Press, New York, NY.

Duijm, N.J., F. Markert, and J.L. Paulsen, 2005, Safety Assessment of Ammonia as a Transport Fuel, Rise-R-1504 (EN), Rise National Laboratory Report, Denmark, Feb.

DOE: U.S. Department of Energy, 2006, Energy Demand on Water Resources: Interdependency of Energy and Water, Report to Congress.

Dugger, G.L., et al, 1980, “ALCLAD-Aluminum, Folded-Tube Heat Exchangers for Ocean Thermal Energy Conversion," APL/JHU AEO-81-32, presented at 3rd Miami International Conference on Alternative Energy Sources, Miami Beach, Florida, Dec.

Energetics, Inc., 2000, Energy and Environmental Profile of the U.S. Chemical Industry, prepared by Energetics, Inc., Columbia, MD, for U.S. Department of Energy, Office of Industrial Technologies.

Ettouney, H.M., H.T. El-Dessouky, and I. Alatiqi, 1999, "Understanding Thermal Desalination," Chemical Engineering Progress 31:43-54, Sept.

George, J.F., and D. Richards, 1980, Baseline Designs of Moored and Grazed 40-MW OTEC Plants - Volumes $A$ and B, JHU/APL Report SR-80-1A, Johns Hopkins University Applied Physics Laboratory, Laurel, MD, June.

Gosnell, J., 2006, "Efficient Ammonia Production," presentation at the Ammonia Fuel Conference, Argonne National Laboratory, Argonne, IL, Oct.

Hacker, V., and K. Kordesch, 2003, “Ammonia cracker," pp. 121-127 in Handbook of Fuel Cells - Fundamentals, Technology and Applications, W. Vielstich, A. Lamm, and H.A. Gasteinger (editors), John Wiley \& Sons Ltd., Chichester, UK.

Hirsch, R.L., R. Bezdec, and R. Wendling, 2005, Peaking of World Oil Production: Impacts, Mitigation and Risk Management, prepared by Science Application International Corporation (SAIC) under Contract \#DE-AM26-99FT40575 with the National Energy Technology Laboratory.

Hoffman, A., 2005, Water Security: A Growing Crisis, How Renewable Energy Can Play a Key Role in Meeting this Challenge, Solar Today, pp. 24-27, July/Aug. 
Hubbert, M.K., 1956, "Nuclear Energy and Fossil Fuels," pp. 7-25 in Proceedings of the American Petroleum Institute Drilling and Production Practice Spring Meeting, San Antonio.

Leiner and Associates, 1997, Survey of Costs and Water Rates for Desalination and Membrane Softning Plants, Water Treatment Technology Report \#24, prepared for U.S. Bureau of Reclamation, Boca Raton, FL, July.

Ophir, A., and A. Gendel, 2000, "Development of the World's Largest Multi-Effect Mechanical Vapor Compression Desalination Plant," Desalination \& Water Reuse 54:50-54, February/March.

Panchal, C.B., 1984, "Heat Transfer with Phase Change in Plate-Fin Heat Exchangers," AIChE Symposium Series 236 - Heat Transfer 80:90-97.

Panchal, C.B., and K.J. Bell, 1987, "Simultaneous Production of Desalinated Water and Power Using a Hybrid-Cycle OTEC Plant," Journal of Solar Energy Engineering 109:156-160.

Panchal, C.B., P. Pandolfini, and W. Kumm, 2007, "Technical and Economic Viabilities of Ocean Thermal Energy Plantships," paper 94e in Proceedings of the AIChE National Meeting, Houston.

Panchal, C.B., et al., 1981, OTEC Performance Tests of the Trane Plate-Fin Heat Exchanger, ANL/OTEC-PS-8, Argonne National Laboratory, Argonne, IL, April.

Panchal, C.B., et al., 1980, OTEC Biofouling and Corrosion Study at the Natural Energy Laboratory of Hawaii, 1983-1987, ANL/ESD-10, Argonne National Laboratory, Argonne, IL, Oct.

Pandolfini, P.P. et al., 1980, "Tests of the APL/JHU Folded-Tube, OTEC Heat Exchanger Core Unit," Heat Transfer in Ocean Thermal Energy Conversion Systems, American Society of Mechanical Engineers Heat Transfer Division, Vol. 12.

Pandolfini, P.P., et al., 1981, "Test Results for the APL/JHU Folded-Tube Aluminum Condenser," Journal of Energy 5(6):394-400, American Institute of Aeronautics and Astronautics.

Rabas, T., C.B. Panchal, and L. Genens, 1990, "Design and Cost of Near-Term OTEC Plants for the Production of Desalinated Water and Power," Solar Energy in 1990's, ASME Publication, Solar Energy Division, Vol. 1.

Shinnar, R., and F. Citro, 2007, "Upfront, Efficient Technology Evaluation," Chemical Engineering Progress 103:10-13, Feb.

Simmons, M.R., 2005, Twilight in the Desert, John Wiley \& Sons, Inc., Hoboken, NJ. 
Stevens, H.C., L. Genens, and C.B. Panchal, 1984, "Conceptual Design of a 10 MWe ShoreBased OTEC Plant," ASME Paper 84-WA/Sol-31, presented at ASME Winter Annual Meeting, New Orleans, LA, Dec.

Vega, L., 1992, "Economics of Ocean Thermal Energy Conversion (OTEC)," Chapter 7 in Ocean Energy Recover, "The State of the Art," American Society of Civil Engineers (ASCE) Publications, Reston, VA.

Yung, D.T., et al., 1981, OTEC Performance Tests of the Johns Hopkins University/Applied Physics Laboratory Folded-Tube Heat Exchanger, ANL/OTEC-PS-9, Argonne National Laboratory, Argonne, IL, Aug. 

Argonne

Energy Systems Division

Argonne National Laboratory

9700 South Cass Avenue, Bldg. 362

Argonne, IL 60439-4815

www.anl.gov 